\title{
UN COMPLEJO DE ALMACENAMIENTO DEL PERIODO INCA EN PACHACAMAC
}

Peter Eeckhout*
Universidad Libre de Bruselas
peeckhou@ulb.ac.be
Milton Luján Dávila*
Universidad Nacional Federico Villarreal
miltonrld@gmail.com

* Peter Eeckhout es doctor en Filosofía y Letras, con orientación a la Historia del Arte y Arqueología en la Université Libre de Bruxelles. Ha publicado Pachacamac durant l'Intermédiaire récent. Etude d'un site monumental préhispanique de la Côte centrale du Pérou (Oxford: B.A.R International Series, 747, Tempvs Reparatvm, 1999) y editado Arqueología de la Costa Central del Perú en los Periodos Tardíos (Lima: Instituto Francés de Estudios Andinos, 2004). Desde 1999 es profesor de Historia del Arte y Arqueología en la Universidad de Bruselas. Es coordinador del programa Precolombino para estudiantes de Historia del Arte y Arqueología. Ha sido responsable de diversos equipos de investigaciones, como Ychsma Project-Archaeological Investigation and Architectural Restoration at Pachacamac, Perú. Ha participado en diversas sociedades científicas ocupando el cargo de presidente, como Société des Américanistes de Belgique, Belgian Center for Peruvian Studies.

* Milton Luján Dávila es bachiller en Historia y licenciado en Arqueología por la Universidad Nacional Federico Villarreal con la tesis Ritual funerario en la costa centro sur. Ha publicado artículos sobre arquitectura y teoría funeraria del periodo Intermedio Temprano. Asimismo, ha desarrollado proyectos de investigación arqueológica de épocas tardías en la sierra de Canta y la vertiente alta del Mantaro. Es codirector del Pia Ychsma Pachacamac, El Palacio-Cajamarca y Paraco Cochayoc, región Ancash. 
Resumen: Los Incas desarrollaron una política económica basada en el control de recursos y fuerza de trabajo en las diferentes partes de su territorio. Esto se nota por la presencia de los famosos tambos y centros administrativos, así como las transformaciones impuestas en sitios existentes. Estas tres categorías de asentamientos presentan una serie de rasgos directamente relacionados con la economía y la logística imperial. Entre estos rasgos figuran los depósitos, la presencia de funcionarios oficiales y los accesos al sistema vial (el famoso Qapaq Nan). Curiosamente, no hay — hasta la fecha - evidencia arqueológica precisa ni investigación específicamente dedicada al papel económico del sitio de Pachacamac bajo el Incanato. En el marco de este ensayo, proponemos contribuir a llenar este vacío gracias a los datos obtenidos durante las dos últimas temporadas de excavaciones del proyecto Ychsma. Luego de una breve presentación del sitio y de sus componentes mayores, veremos cuáles son los edificios y sectores relacionados con la economía inca y nos enfocaremos sobre uno de ellos, llamado Edificio E8. El relato descriptivo de las excavaciones llevadas en este conjunto y los hallazgos que se encontraron servirán de base para la discusión.

Palabras Clave: Inca, Pachacamac, economía prehispánica, Andes, Perú, qollcas, almacenes, Horizonte Tardío.

\section{A COMPLEX OF STORAGE AREA IN THE INCA PERIOD ON PACHACAMAC}

ABstract: The Incas promoted an economic policy based on the control of resources and labor in different parts of their territory. This is particularly noticeable by the presence of the famous tambos and other administrative centers, as well as transformations in existing sites. The settlements show a number of features directly related to imperial economy and logistics such 
as warehouses, state functionaries and a road system access (Qapaq Nan is one of the most famous). Surprisingly, there is neither precise archaeological evidence nor specific research about the economic role of Pachacamac in the Inca times. Within the framework of this paper, we aim to fill this gap as a result of the data collected during the two last periods of Ychsma project. After a brief presentation of the site and its major components, we will identify the buildings and sectors related to the Inca economy and focus on one of them, specifically on Building E8. The descriptive account of the excavations carried out in this building and the findings made will be the grounds for discussing about the Inca economy.

KeYwords: Inca, Pachacamac, prehispanic economy, Andes, Peru, qollcas, warehouses, Late Horizon.

\section{INTRODUCCIÓN}

Tos Incas desarrollaron una política económica basada en el control de recursos y fuerza de trabajo en las diferentes partes de su territorio. Esto se nota por la presencia de los famosos tambos y centros administrativos, así como las transformaciones impuestas en sitios existentes. Estas tres categorías de asentamientos presentan una serie de rasgos directamente relacionados con la economía y la logística imperial, entre estos rasgos figuran: (a) los depósitos, (b)la presencia de funcionarios oficiales y (c) los accesos al sistema vial (el famoso Qapaq Ñan). Son aspectos que se evocan desde los inicios de la conquista.

En el caso de Pachacamac, los primeros relatos hablan del tema, pues en enero de 1533, Hernando Pizarro (1533) llega a la zona y revela que «en todos los llanos y más allá no tributan al Cuzco sino a la mezquita». Esta cita refleja la organización descentralizada del Imperio Inca. En efecto, varios autores lo 
subrayaron, en el Cuzco no se contaba con una población numerosa, al contrario de otras capitales de imperios antiguos como Roma. Por lo tanto, no había necesidad de llevar enormes cantidades de bienes desde los diversos lugares del Imperio, sino lo suficiente para algunos miles de cuzqueños, los cuales obtenían muchos de sus recursos en el área nuclear.

Los depósitos, llamados qollcas en quechua, servían para almacenar diferentes tipos de bienes. Estos bienes servían para diversos fines, como los siguientes: (a) mantenimiento de los ejércitos imperiales en tránsito, (b) abastecimiento de los trabajadores en tiempos de mita, (c) redistribución a la población local bajo la forma de banquetes y fiestas, o (d) en momentos difíciles como las malas cosechas.

Craig Morris (1967) ha estudiado las qollcas de Huánuco Pampa, y llegó a la conclusión que su forma (circular o cuadrangular) podría tener relación con lo que contenían, sobre todo, por el alto grado de elaboración de estos depósitos, equipados con sistemas de ventilación y otros dispositivos para favorecer la conservación óptima de los bienes perecederos. Así como él otros se dedican más que todo a las qollqas serranas, las cuales son formalmente diferentes de los depósitos encontrados en sitios costeños: es decir en el litoral y valles bajos. Basta citar el ejemplo de Chan Chan, cuyos almacenes se encuentran adentro de las ciudadelas y palacios Chimú, y no afuera de la ciudad, como en numerosos casos serranos.

Los depósitos costeños difieren muy a menudo por su sistema de acceso, que no es por medio de una puerta baja, como en la sierra, sino por la cima de los muros, por medio de escaleras. Las dimensiones también varían mucho, y por lo general los sistemas de almacenamiento costeños presentan un tamaño individual más grande que los ejemplos serranos. Estas características aparecen en Pachacamac, donde tenemos varios ejemplos de 
depósitos que corresponden a los periodos Intermedio Tardío y Horizonte Tardío.

Los ejemplos fechados del Intermedio Tardío se encuentran sistemáticamente asociados a edificios mayores, como las pirámides con rampa. En términos formales, todos son octogonales, generalmente cuadrados y estrechamente asociados a la parte privada. Su acceso estuvo controlado por los habitantes principales de las pirámides, como lo enseña el estudio del sistema de tránsito interno de los edificios. Esto difiere mucho del patrón inca, donde los depósitos, ubicados afuera del centro de los sitios - generalmente en un lugar alto y fresco-, no evidencian un control de acceso tan estrecho. También resalta la capacidad relativamente reducida de los depósitos de Pachacamac, pues de ninguna manera se pueden comparar con los cientos de qollqas de Huánuco Pampa, a pesar que ambos sitios se parecen en tamaño e importancia.

Estas dos peculiaridades sugieren que lo que se almacenaba en Pachacamac fue una parte selecta de los bienes de consumo, posiblemente reservados a un segmento específico de la población, quien lo cuidaba con precauciones. Este patrón especial también demuestra que el manejo de los depósitos no estaba en las manos de un poder, abarcando todo el sitio, sino que estuvo dividido entre las diversas pirámides con rampa, la mayoría de las cuales se abandonaron antes del Horizonte Tardío (Eeckhout 2012). Por lo tanto, no hay, a la fecha, evidencia arqueológica precisa, ni investigación específicamente dedicada al papel económico del sitio bajo el Incanato.

En el marco de este ensayo, proponemos contribuir a llenar este vacío. Esto es posible gracias a los datos recolectados durante las dos últimas temporadas de excavaciones del proyecto Ychsma en Pachacamac. 
Luego de una breve presentación del sitio y de sus componentes mayores, veremos cuáles son los edificios y sectores relacionados con la economía inca y nos enfocaremos sobre uno de ellos, llamado Edificio 8 (E8). El relato descriptivo de las excavaciones llevadas en este conjunto y los hallazgos que se encontraron servirán de base para la discusión.

\section{EL SITIO DE PACHACAMAC}

Pachacamac se encuentra sobre la margen derecha del río Lurín y cerca de su desembocadura, a medio kilómetro del Océano Pacífico. El sitio cubre una superficie total de 572 hectáreas, cuyo tercio está ocupado por los edificios del sector monumental (ver Figura 1).

El sitio se divide en cuatro zonas principales, definidas por dos murallas concéntricas y dos murallas exteriores. La primera muralla o Muralla Sagrada incluye el Templo Viejo de Pachacamac, el Edificio Pintado, el Templo del Sol, un importante cementerio y una estructura cuadrangular muy destruida (ver Figura 1). La segunda muralla contiene vías de comunicación, cementerios, numerosas plazas y canchas, estructuras diversas, así como edificios monumentales construidos en adobe y en tapial bajo el mismo modelo arquitectónico. Ese modelo, conocido con el nombre de "pirámide con rampa", ha sido presentado y discutido en otros ensayos. Existen dieciséis conjuntos de pirámides con rampa en el sitio de Pachacamac y otras más en el valle de Lurín y en los valles vecinos. La mayoría de los autores considera que estas construcciones se remontan al periodo Intermedio Tardío (ca 900-1470 d.n.e.), cuando el sitio llevaba el nombre de la divinidad principal de la Costa Central, Ychsma, siendo luego rebautizado como Pachacamac por los Incas en el Horizonte Tardío (Eeckhout 1993; Rostworowski 1972, 1992). Casi todas las pirámides con 
rampa se encuentran en el interior de la segunda muralla, exceptuando las pirámides $\mathrm{N}$. v y N. VIII, que están ubicadas en la zona desértica, separando la segunda muralla de la tercera, que es la exterior. Existe una cuarta muralla, al norte, a $1 \mathrm{~km}$ de la tercera.

Cuando el sitio fue conquistado por los Incas, Topa Inca Yupanqui emprende muchas transformaciones en el lugar. Estas transformaciones son motivadas, entre otros, por la voluntad de hacer del sitio un centro de peregrinaje a nivel imperial. La Plaza de los Peregrinos, el Templo del Sol y la casa de las Mamaconas se edifican en lugares antes ocupados por construcciones locales. Por lo que concierne a los depósitos, existe una serie de estructuras cuyo diseño podría corresponder con esta función en las gradas del Templo del Sol, pero su estado actual de conservación no permite muchos comentarios al respecto. También hay algunos probables depósitos asociados al Acllahuasi, pero según nuestras investigaciones, los sistemas de almacenamiento incas, observables hoy, se concentran principalmente en dos lugares: los alrededores de la Plaza de los Peregrinos - especialmente los edificios A1y A2 - y la zona norte del sitio monumental, donde hemos identificado una estructura muy peculiar, llamada E8.

El conjunto A1 se extiende al norte de la Plaza de Peregrinos y consta de una serie de plazas, patios, ambientes y recintos hundidos dispuestos en varios niveles. Se trata de una construcción imponente, más probablemente relacionada con el manejo de las actividades ceremoniales y de las ofrendas llevadas por los peregrinos. No se ha excavado este lugar, pero las limpiezas superficiales han permitido descubrir evidencias arquitectónicas que sugieren la función de almacenaje, como filas de recintos hundidos asociados con dispositivos de control de acceso, por ejemplo. La ausencia de datos de excavación en el edificio mismo dificulta su ubicación cronológica. Sin 
embargo, se encontraron evidencias relacionadas con el Horizonte Tardío, por ejemplo un aríbalo en la esquina de un cuarto del edificio. Además, el A1 y el A2 vecino, están asociados de manera obvia a la Plaza de los Peregrinos, cuyas excavaciones han demostrado que fue construida en la época inca.

El Edificio E8, ubicado en el extremo norte del sitio, se identificó en el 2008 y se excavó de manera extensiva en el 2012. Los resultados de estas investigaciones se detallan a continuación.

\subsection{El Edificio E8}

El Edificio E8 se encuentra en el barrio E de Pachacamac, es decir, en el extremo norte del sitio. Se trata de una estructura aislada, pero asociada con sistemas de tránsito de los cuales solo quedan vestigios: un muro con camino epimural al este y el trazo de una calle o pasaje al oeste.

Aunque ha sido parcialmente destruido por la Antigua Panamericana y el cerco vivo de concreto que delimita el sector monumental del sitio, los componentes principales del E8 están conservados y su forma global pueden ser reconstituidos. La maqueta numérica que presentamos ilustra lo realizado en base a los datos de campo (ver Figura 2).

El Edificio 8 tiene forma general rectangular y estuvo al parecer completamente cerrado por un muro de $2 \mathrm{~m}$ de ancho, con un acceso en el suroeste. Se compone básicamente de dos partes: un gran patio de 80 $\mathrm{m} \times 60 \mathrm{~m}$, asociado a una serie de recintos hundidos de forma cuadrada y dispuesto en dos filas paralelas de 10 unidades por el lado sur del patio. Según las evidencias observables, el acceso a los recintos se hacía por caminos epimurales. Se observa también un cuarto en la parte delantera, sobre el cual volveremos más adelante. 


\subsection{DESCRIPCIÓN DE LAS EXCAVACIONES}

Para comprobar la hipótesis del uso de este edificio como tambo resulta importante definir el tipo de ocupación en cada uno de sus sectores. Por lo tanto, se programaron excavaciones sistemáticas de todos los recintos o depósitos (U101-U120), así como de la antecámara (U99) y de la entrada al complejo (U122).

Para esclarecer el tema de la fundación del complejo se excavó también una unidad en la parte externa del muro sur (U121). La excavación realizada abarcó un área de tamaño medio cerca a la entrada (U122) y otro cerca a la antecámara (U99) (ver Figura 3).

\subsection{El CUARTO DEL Quipucamayoc (UNidAd 99)}

Durante los trabajos llevados a cabo en el marco del levantamiento tridimensional del sitio monumental (2002-2008), se había encontrado en la superficie fragmentos de quipus y una vasija grande de tipo desconocido que sugerían que la estructura estaba relacionada con alguna forma de gestión (ver Figuras 4 y 5), además de estar ubicada cerca a los supuestos depósitos U101 a U120. Se decidió excavar en este lugar con fines de verificar la hipótesis y recolectar evidencias sobre el uso del patio. Se excavó un rectángulo de $6 \mathrm{~m} \times 7 \mathrm{~m}$, es decir, $42 \mathrm{~m}^{2}$, abarcando la estructura y parte del patio en sus lados oeste, norte y este (ver Figura 6).

- Capa superficial: Arena eólica gris claro y tierra gris oscuro sueltas a semicompactas, de unos $12 \mathrm{~cm}$ a $60 \mathrm{~cm}$ de espesor, con un fuerte declive de sur a norte. Contuvo escaso material cultural como unos tiestos diagnósticos (incluido un fragmento negro escultórico de 
cabeza), y escaso material orgánico (conchas, vegetales entrelazados, una mazorca carbonizada), concentrados en la parte sureste de la unidad.

- Capa 1: Derrumbe de adobes colapsados mezclados con fragmentos de adobes, arena y tierra gris semicompacto de espesor variable que alcanzó 1,20 m de altura. El colapso parece haberse producido en el sentido sureste a noroeste, pero no se puede precisar si se hizo en un solo momento o varios. Los adobes son de tamaño grande (por ejemplo $50 \mathrm{~cm} \times 30 \mathrm{~cm} \times 20 \mathrm{~cm}$ de alto), evidentemente de filiación cultural inca.

Al retirar la capa 1 se pudo apreciar una estructura arquitectónica en mal estado de conservación. Esta se encontraba adosada al muro de la U112.

Esta estructura tiene aproximadamente $5 \mathrm{~m}$ de largo x $3 \mathrm{~m}$ de ancho, orientada hacia el patio, con muros de aproximadamente $90 \mathrm{~cm}$ de ancho y con recintos en la parte superior. Tiene un vano de acceso central asociado a una escalinata que baja en dirección noroeste (patio). El vano llega a un ambiente divido en dos por un muro bajo. El recinto oeste tiene vano de acceso y dos niveles de piso formando una banqueta, así como un nicho con enlucido en el muro oeste. El recinto este es de planta rectangular. Todos los muros son enlucidos en ambas caras.

Adentro de la estructura se hallaron tiestos de grandes dimensiones, color rojizo-crema, que aparenta tener la forma de una chullpa tipo serrano (ver foto y dibujo). También se hallaron fragmentos de spondylus sobre el muro sureste, así como el Hallazgo 13: quipu fragmentado de algodón blanco con unas cuerdas de hilo 
blanco y marrón, y otros blanco y verde. El quipu se encontraba debajo de un adobe colapsado cerca de la esquina exterior noroeste de la estructura. Otro quipu en mejor estado de conservación (Hallazgo 18) se encontró entre los escombros, por el lado sureste al exterior de la estructura. Muestra restos de tinte morado que habrían procedido de concholepas.

A partir de este nivel se excavó una cuadrícula en la esquina interna este de la estructura (cuadrícula a) y también en el resto de la unidad fuera de la estructura. Se trata, pues, de dos contextos diferentes, con estratigrafías distintas, y por lo tanto los presentamos de manera separada (ver Figura 7)

Interior del cuarto (U99-a):

- Capa 2: Piso 1, de barro arcilloso beige compacto de unos $10 \mathrm{~cm} \mathrm{de}$ espesor, muy desgastado por el uso y sobre todo por estar removido. No hubo material asociado, salvo algunas corontas de maíz.

- Capa 3: Relleno suelto de arena gris, fragmentos de adobes superpuestos sueltos sin argamasa de menor tamaño que la capa anterior. Hubo escaso material cultural (tiestos llanos y un fragmento con diseño zoomorfo negro sobre rojo), mayor presencia de restos botánicos (mazorcas de maíz, tallos de zapallo) escasa presencia de restos malacológicos y huesos, estrato que alcanzó aproximadamente $70 \mathrm{~cm}$.).

Se pudo evidenciar que la estructura (U99) descansa sobre un relleno de arena, probablemente precedido de contextos botánicos, hallados entre adobes alineados y superpuestos. Además los muros que encierran la estructura debajo del piso están conformados por 
adobes y terrones. El muro suroeste del depósito (U112), descansa sobre otro muro más ancho, en la cual descansarían los depósitos (U102, 104, 106 y 108), que recorre probablemente de oeste a este pasando a su vez por debajo de los depósitos (U110, U 112, U114, U116, U118 y U120). Esta técnica constructiva se pudo observar en la U101, esto supone que estos muros anchos inferiores tenían como función soportar a los muros más delgados del E8.

- Capa 4: Arena suelta marrón de grano grueso. Se detuvo la excavación.

Excavaciones al exterior de la unidad U99

- Capa 2: Conformado por tierra y arena de grano fino, gris y claro, de consistencia suelta a semicompacta y compacta en ciertos espacios. El material cultural hallado fue regular, conformado por tiestos llanos y diagnósticos de tipo Inca local e Ychsma tardío. Dicho material, asociado a restos orgánicos, incluye estiércol de ganado (vacuno, equino y porcino) en superficie; mientras que frente al ingreso de la estructura e interior del estrato se hallaron muchos restos botánicos, conformados por mazorcas y granos sueltos de maíz, zapallo, frejol, ramas de vegetales, trozos de mates, lúcuma, tubérculos (tipo papas), gran proporción de maní.

Hay dos áreas de quema por cada lado de la escalinata o rampa muy desgastada: solo quedan las paredes laterales de dos hileras de altura que pudieron dar acceso al vano en la parte superior de la estructura. Sin embargo, esta escalinata o rampa es más tardía.

Esto se deduce por lo siguiente: (a) su base está encima de la 
hilada inferior del muro de la estructura y (b) está sentada encima y al interior de la capa 2.

- Capa 3: Se inició a partir del piso 1 de barro arcilloso gris compacto de aproximadamente 5 a $7 \mathrm{~cm}$ de espesor, muy desgastado en un $70 \%$ de la zona excavada. El material es menos denso que en la capa superior, consta de tiestos naranjos llanos y otros diagnósticos (negro con bandas blancas), a veces con restos de hollín, 1 fragmento de textil llano de 1x1, y escaso material botánico (maní, junco, papa, mazorca de maíz, mate y algodón). En la superficie del piso, en la esquina sureste de la unidad se encontró el Hallazgo 19: un petate de junco entrelazado de $39 \mathrm{~cm}$ x $53 \mathrm{~cm}$ con soportes de ramas y lazos de algodón. Al noreste de la cuadrícula se encontró el Hallazgo 20 (ver Figura 8), conformado por dos ovillos de hilo beige, marrón y crema. Restos de cabello incrustados en los ovillos. Es posible que se tratara de la materia prima para fabricar las cuerdas de los quipus como los encontrados en la parte superior de la estratigrafía, ya que los hilos fueron muy similares.

Los muros de la estructura descansan sobre este piso al cual están asociados.

- Capa 4: Piso 2 irregular de arcilla blanca compacta muy desgastado, descansa sobre una capa de arena gris suelta de $10 \mathrm{~cm}$ de espesor, no hubo material asociado.

- Capa 5: Piso 3 muy bien conformado de tipo arcilloso crema de consistencia compacta sin huellas de desgaste por uso, muy bien conservado en el edificio E8. 
Comentarios e interpretación sobre las excavaciones en el cuarto del Quipucapayoc

a) Se pueden distinguir superposiciones de pisos y posiblemente una remodelación arquitectónica.

b) Ocupación pre E8 (capas 4 y 5).

c) Fundación y ocupación de la estructura del Quipucamayoc (capa 3, piso 1, y parte de la capa 2 afuera de la estructura).

d) Abandono (capas 2 -exterior de la estructura-, 1 y 0 ).

No hay posibilidad de fechar la etapa 1 en el momento. No se explica cómo se accedía a la parte superior de la estructura en la fase inicial de construcción (etapa 2), ya que la escalinata es más tardía y no se observa remodelación del acceso mismo. Sin embargo, la observación atenta de la pared norte de la estructura puede proporcionar cierta hipótesis. En efecto, se ven huellas de desgaste en todo este frontis, salvo en la parte central debajo del acceso, como si esta parte hubiera sido más protegida. La forma y el tamaño de la zona, así preservada, es más grande que la escalinata tardía, y adopta más bien una forma particular. Podría tratarse de otra forma de acceso, tipo escalera lateral, por ejemplo, que fue destrozada en algún momento, y luego reemplazada por la escalinata frontal tardía, la cual a su vez fue destrozada (ver Figura 9).

El relleno dentro de la estructura consta de adobes. Estos probablemente proceden de la destrucción de alguna estructura anterior de filiación local. La composición del piso adentro de la estructura se parece mucho a los pisos de los depósitos.

La presencia de fragmentos de spondylus en la capa de escombros se puede relacionar con los otros spondylus encontrados en capas arqueológicas 
intactas en los depósitos adyacentes. Los diferentes quipus y otras evidencias encontradas cerca de la estructura confirmaron una estrecha relación con un área de almacenamiento. El cuarto delantero es un pequeño ambiente rectangular de unos $12 \mathrm{~m}^{2}$ con una sola entrada en dirección al patio. Al ingresar, se puede observar una subdivisión del espacio interno en dos partes, como si fuera un vestíbulo con un pequeño ambiente adyacente con banqueta lateral. Aunque ha sufrido de un saqueo, la limpieza del cuarto hasta el piso ha revelado hallazgos muy instructivos, los cuales detallamos a continuación:

- Primero: Un pequeño vaso de madera finamente decorado por motivos incisos de plantas de maíz, muy recurrente en la iconografía inca (ver Figura 10). Dicha iconografía sugiere que este objeto sirvió más, probablemente, para tomar chicha. Una práctica ligada a las fiestas y ceremonias para la mayoría de la gente, y de consumo diario para ciertas clases privilegiadas como los curacas y altos funcionarios del Estado (Bray 2003).

- Segundo: Se encontró tirado en el suelo y roto en varias docenas de pedazos una pieza de cerámica reconstituida al 80\%. Pesa unos 10 kilos y tiene forma totalmente inusual, al parecer representaría una chulpa (ver Figura 5). Se trata de una vasija rectangular con salientes en el techo, en los cuatro lados 2 dinteles que salen en los extremos superiores, un orificio circular en la parte central del techo y 2 apéndices con ocho orificios de $2 \mathrm{~mm}$, uno de ellos solo se presenta hasta la parte media. La pasta es naranja oscura, muy homogénea. La pieza está pintada de blanco y no muestra huellas de quema ni de cualquier contenido. No sabemos cuál fue el uso de 
este objeto, tal vez se trata de una especie de maqueta. Otra opción sería que quizás servía para guardar khipus (cf. Flores Ochoa et. al. 2007: 243) (ver Figura 4)

- Tercero: el tercer hallazgo remarcable del contexto es una colección de khipus, algunos con hilos de color, tirados en el suelo. Desafortunadamente, estos khipus se encontraron en mal estado de conservación y han sido fragilizados por haber sido expuestos a la humedad (ver Figura 4). Sin embargo, esperamos recuperar los datos objetivos significativos (número, posición y tipo de nudos) para que se puedan usar estos khipus para fines científicos. Uno de los khipus está doblado y amarrado, como suelen hacer los khipucamayoq para conservar sus khipus. Esto, junto con la presencia del kero de madera decorado y el contexto general, lleva a la conclusión que este cuarto estuvo ocupado por un funcionario, quien se dedicaba a gestionar los bienes que llegaban al Edificio E8, estratégicamente ubicado al límite de la zona monumental. Los bienes depositados en el patio, tal vez por caravanas de llamas (lo que explicaría el ancho del acceso), estaban registrados y luego guardados en los depósitos vecinos.

\section{LOS DEPÓSITOS (U101-120)}

Las excavaciones tuvieron como meta la recolección de las evidencias respecto al contenido original de los depósitos. Para fines de estudios arqueo-botánicos hemos usado de zarandas especiales para los sedimentos, y hemos recolectado muestras de sedimentos para flotación (ver Figura 18). 
Resultó que todos los depósitos, con pocas excepciones, presentan la misma secuencia estratigráfica. Por lo tanto, para evitar repeticiones fastidiosas, vamos primero a presentar un ejemplo-tipo, el depósito U-111, el cual puede ser considerado el más representativo del conjunto.

- Capa superficial: Estuvieron cubiertos de arena eólica gris suelta y fina de $10 \mathrm{~cm}$ de espesor, siendo más ancha en el centro de la unidad. El material consta de regular cantidad de corontas de maíz (algunos con granos), chala de maíz, tallos de pacae, cáscaras de maíz y semillas de lúcuma, todo esparcido de manera irregular en la capa. También aparecen fragmentos de material malacológico muy diminutos y restos de huesos de roedores. El material cultural consta de tiestos llanos de pasta naranja local, probablemente Ychsma Tardío, y basura moderna.

$\mathrm{Al}$ retirar la capa se dejó expuesto el colapso de los adobes que conformaron parte de los muros del recinto, asimismo, se dejaron partes intactas.

- Capa 1: Colapso de adobes que formaron parte de los muros, mezclados con arena eólica fina gris de consistencia suelta, tierra fina suelta a semicompacta beige, de $20 \mathrm{~cm}$ de espesor. El escaso material asociado consta de tiestos llanos, papel periódico, malacológicos y fragmentos de hueso. Al retirar la capa de derrumbe las dimensiones internas precisas del recinto 111 aparecen claramente : (a) Lado $\mathrm{N}$ : 5,6 m; (b) Lado E: 5,7 m; (c) Lado S: 5,6 m y (d) Lado O: 5,7 m.

- Capa 2A: Estuvo conformado por arena eólica oscura de grano fino mezclada con fragmentos de mortero de barro suelta en $80 \%$ y más compacta en zonas donde los adobes se hallaron rotos, sea 
en partes más cercanas a los muros colapsados. La capa mide 20 $\mathrm{cm}$ a $30 \mathrm{~cm}$ de espesor y contiene escaso material cultural (tiestos pequeños, papel moderno) y escasa cantidad de material orgánico (huesos, mandíbula, corontas, malacológicos, etc.) esparcido en toda la capa, con mayor cantidad de maíz. En la esquina suroeste, la capa se prolonga hasta el piso 1 , así que no hay capa $2 \mathrm{~B}$ en esta parte, probablemente por una remoción posterior.

Cabe resaltar que el límite inferior de la capa $2 \mathrm{~A}$ corresponde con la aparición del enlucido en los muros, en buen estado de conservación (ver capa 2B). Por lo tanto, se puede deducir que esta capa $2 \mathrm{~A}$ corresponde al periodo de abandono del lugar, con acción destructora de la erosión eólica que afectó las partes expuestas de los muros.

- Capa 2B: Arena suelta gris, marrón de $20 \mathrm{~cm}$ a $25 \mathrm{~cm}$ de espesor, con regular cantidad de restos orgánicos, especialmente mazorcas de maíz con granos y sin ellos, en toda la capa. En ciertas zonas, cerca de los muros, se nota el endurecimiento de la arena por efecto de la lluvia y la humedad. Se nota también que las paredes internas del recinto fueron todas enlucidas con barro fino, cuyo estado de conservación es bueno por haber estado cubiertos por la capa $2 \mathrm{~B}$.

- Capa 3: Piso 1 de barro compacto, poroso, beige claro de extensión horizontal, relativamente homogéneo, con depresiones de desgaste, unido por un revoque a la parte inferior del enlucido de los muros.

La secuencia estratigráfica que acabamos de describir se repite en los demás depósitos. Hay que subrayar que los depósitos contenían maní, ají, zapallo macre y loche, frijol, algodón, lúcuma, guayaba, maíz (Stellian 2012). También, se hallaron restos no identificados probablemente pertenecientes 
al género de los ajíes, zapallos, algarrobo, Bidens sp, Chenopodium sp, aguaymantos, Sonchus sp, o familia de las asteráceas, gramíneas, portuláceas. Además de la presencia de maderos, carbón, tallo y hojas desconocidas, se hallaron posibles restos de frijol, guayaba, pallar, cierta especie del género de los zapallos, Nicotiana sp, Panicum sp, aguaymantos de la familia de las cactáceas, frijoles. Finalmente, se encontraron restos desconocidos UnkYch-55, 57 a 60, 66, 70, 71 y 74. La frecuencia mayor fue la presencia de maíz (98,04\%), seguido del maní (66,67\%), ají (54,9\%), madera (50,98\%), carbón $(47,06 \%)$, zapallo loche $(41,18 \%)$, algodón $(37,25 \%)$ y guayaba $(37,25 \%)$. También se encontró presencia de lúcuma $(21,57 \%)$, mate $(17,65 \%)$, zapallo macre y calabaza $(11,76 \%)$, el frijol tienen una frecuencia de $11,76 \%$. De acuerdo a esto podríamos decir que no hubo elección de una determinada especie para ser depositada, por cuanto el análisis arroja una cierta variedad de elementos botánicos en cada depósito (ver Tabla 1). Asimismo, se encontraron en los depósitos una serie de hallazgos y casos excepcionales que vamos a detallar en seguida (ver Figura 11).

La presencia de los hallazgos de spondylus sp fueron encontrados en cuatro zonas. Estas son las siguientes: (a) Hallazgo 14 spondylus $s p$ de $10 \mathrm{~cm}$ de ancho por $11 \mathrm{~cm}$ de largo, ubicado al interior de la capa $2 \mathrm{~B}$ en contacto con el piso 1 de la Unidad (U107); (b) Hallazgo 10 valvas de spondylus, hallado al interior de la capa $2 \mathrm{~B}$ en contacto con el piso 1 de la unidad (U105), fragmento de spondylus hallado sobre el piso 1 de la unidad (U109); (c) Hallazgo 5 spondylus sp con perforación en su lado inferior, hallado en un hoyo circular de $20 \mathrm{~cm}$ de diámetro, que cortan el piso de la unidad (U104); (d) Hallazgo 16a valva de spondylus hallado en la capa 2b en contacto con el piso 1 de la unidad (U113) (ver Figura12). Asimismo, se hallaron 148 mates de diversos tamaños, colocados boca abajo a manera 
de platos o cuencos distribuidos de manera ordenada en el lado oeste, sobre arena, asociado a una gran cantidad de corontas de maíz, granos sueltos de maíz y cáscaras de maní, a unos $6 \mathrm{~cm}$ del piso del recinto 112 (ver Figura 13).

\subsection{COMENTARIOS E INTERPRETACIÓN RESPECTO A LAS EXCAVACIONES EN LOS DEPÓSITOS}

Se distinguen de acuerdo a los pisos hasta dos etapas refacción y 1 remodelación:
a) Fundación en base a los muros anchos (capa 4) para adelante.
b) Construcción de los depósitos (capas 3 y 2B).
c) Abandono y derrumbe (capas $2 \mathrm{~A}, 1$ y 0 ).

Las muestras recogidas en las capas inferiores deberían proporcionar indicaciones sobre el uso original de la estructura, lo cual en el momento se puede definir como depósito para maíz. Tanto las características del material constructivo como el contexto general indican que la estructura corresponde al periodo Horizonte Tardío.

\section{EL CORREDOR EXTERIOR SUR (UNIDAD 121)}

El diseño general del Edificio E8 y la topografía sugieren que el tránsito desde las afueras del sitio se hacía por un corredor ancho a lo largo del lado oeste, el cual, posiblemente, giraba detrás del muro sur de los depósitos en dirección al barrio E. Se decidió excavar en este lugar con fines de verificar si existía un camino detrás del muro sur, así como la ubicación cronológica de este último en el desarrollo arquitectónico del Edificio E8. 
Se excavó un rectángulo de $3 \mathrm{~m}$ x $1 \mathrm{~m}$ pegado al lado externo del muro sur del Edifico E8, a la altura del recinto E103. Para mayor detalle se sugiere ver las figuras 3 y 14 .

- Capa superficial: Arena eólica gris mezclada con piedras angulosas grandes y gravillas, de consistencia suelta a semicompacta en el lado sureste, aproximadamente de $20 \mathrm{~cm}$ de espesor. El material cultural consta de regular cantidad de tiestos, fragmentos textiles y papel periódico. El material orgánico consta de regular cantidad de semillas diversas, mazorcas de maíz, coprolitos, huesos y malacológicos, todo esparcido en toda la capa.

-Capa 1: Compuesta por los niveles $1 \mathrm{~A}$ y 1B, de $50 \mathrm{~cm}$ de espesor. El nivel 1A se junta y cubre parcialmente al otro en la parte este de la trinchera. Se caracterizó por la presencia de tierra compacta gris mezclada con gravillas y arena, contiene tiestos, fragmentos de textil, maní y tallos en mínima cantidad. El nivel 1B aparece en el noroeste y debajo de 1A. Se compone de tierra suelta gris oscura a marrón mezclada con piedras angulosas. Contiene abundante material cultural (tiestos, pedazos de textil, soguillas, implementos del tejer) y orgánico (maní, semillas de lúcuma y zapallo, ají, tamarindo, malacológicos), así como elementos modernos (periódicos, vidrio, plástico).

- Capa 2: Superficie irregular y compacta conformado por tierra gris y arena eólica marrón con presencia de fragmentos de cerámica, textiles, algodón, semilla de ají, lúcuma y otros frutos, fragmentos de conchas y carbón de unos $10 \mathrm{~cm}$ de espesor. Al medio de la unidad aparece una matriz de forma ovalada de $1,3 \mathrm{~m}$ x $1 \mathrm{~m}$ que 
estuvo sellada, la cual fue rota parcialmente (cf. capa 1B). Al interior se encontró el Hallazgo 3: cántaro blanco, sobre rojo, de unos 45 cm de altura, de estilo Ychsma tardío B, cubierto por un mate y posiblemente asociado a un canto rodado. (Ver Figura 15)

La matriz tuvo más de $1 \mathrm{~m}$ de profundidad atravesando la capa 3. El relleno fue compacto en la parte sur y luego totalmente suelto en el resto de la fosa conformado por tierra con grumos y arena, así como abundante material cultural (tiestos llanos, algodón) y orgánico (carbón, fragmentos de conchas, maní, semillas de zapallo). En el extremo norte de la matriz, a $25 \mathrm{~cm}$ encima de la capa 3, se encontró una alineación de piedras de $25 \mathrm{~cm}$ de alto, 20 $\mathrm{cm}$ de ancho y $30 \mathrm{~cm}$ de largo asociada a carbón y cubiertas por una compactación de tierra y arena.

Un muro de adobes aparece en el borde sur de la trinchera.

- Capa 3: Relleno de tierra y arena gris mezclada con piedras, de consistencia semicompacta a suelta, de $1 \mathrm{~m}$ de espesor. La capa es de extensión irregular, con un fragmento de piso de $10 \mathrm{~cm}$ de largo por el lado noreste (piso 1), asociado por un revoque a la base de piedras (dos hileras) del muro sur del Edificio E8. En el resto de la cuadrícula los desniveles estuvieron cubiertos por arena eólica compacta por las lluvias asociado a cerámica llana y diagnóstica (Horizonte Tardío), así como unos fragmentos de textil. También se encontró mucho carbón y escasos restos orgánicos (malacológico, algodón, semillas diversas, coprolitos y tallos de plantas).

El muro sur mide menos de $1 \mathrm{~m}$ de altura y estuvo asociado al relleno. Por lo tanto, es más tardío que el muro del E8 que constituye el límite norte de la trinchera. Este último tiene 
dos fases constructivas, ya que las piedras unidas con el piso en la parte superior de la capa 3 se superpusieron a un muro de adobes totalmente cubierto por dicha capa.

- Capa 3A: Relleno suelto de tierra gris con piedras blancas-amarillas y grises de aproximadamente $40 \mathrm{~cm}$ de espesor. El material consta de tiestos llanos y diagnósticos (Horizonte Tardío y posiblemente otros), y escasos fragmentos de huesos. El muro sur del E8 sigue bajando, mostrando huellas de erosión debido a la exposición al medio ambiente.

- Capa 4 (Piso 2): Piso compacto relacionado con el piso 1 capa 3 de la U103, muy bien conservado cerca al muro, pero muy desgastado en otras partes, donde se aprecia tierra gris y cascajo suelto no asociado a material cultural, estrato de $14 \mathrm{~cm}$ a $20 \mathrm{~cm}$.

- Capa 5: Relleno suelto de arena fina gris seleccionada de unos 65 $\mathrm{cm}$ de espesor, sin material asociado.

- Capa 6 (Piso 3): Piso compacto de beige a gris, pasa a $4 \mathrm{~cm}$ por debajo del muro sur del E8.

\subsection{Comentarios E INTERPRETACión RESPECTO A LAS EXCAVACIONES EN EL CORREDOR SUR}

Se pueden distinguir cinco etapas:

a) Piso (capa 6) relacionado con el Horizonte Tardío.

b) Piso sobre relleno y construcción del E8 asociado a la cara externa (capas 5 y 4 ).

c) Relleno y construcción de un piso desgastado (capa 3 y muro sur tardío). 
d) Hallazgo 3 asociado al piso, por lo tanto relacionado al uso y función del espacio depósito (capa 2/H3).

e) Abandono (capas 1 y 0 ).

Podemos ver que el E8 fue construido con un piso asociado al lado externo (etapa 2), el cual se rellenó más tarde para construir otro piso $140 \mathrm{~cm}$ encima, asociado a un muro tardío paralelo al muro del E8, conformando, pues, un pasaje de unos $3 \mathrm{~m}$ de ancho (etapa 3). La etapa 4 corresponde probablemente a un cambio drástico de uso, ya que el pasaje fue usado para colocar una ofrenda (H3) (ver Figura 15) que luego se selló con barro y fue cubierta por relleno. Al ser el sello roto y la matriz mucho más amplia que el H3, se supone que el contexto se ofrendó en algún momento, y parte de su contenido fue retirado (etapa 5). El contenido de la capa 1B deja suponer que podría tratarse de un entierro, el cual fue tomado por saqueadores y parte de su ajuar (implementos de tejer) tirado cerca al hueco. Valga la pena remarcar que nuestra excavación abarca exactamente los límites de la matriz del H3, lo que — considerando el tamaño relativamente reducido de nuestro cateo- resulta ser una suerte extraordinaria. Tanta suerte es algo inusual, así como el inesperado y extraño lugar donde se encontró este hallazgo. Por lo tanto, sugerimos que tal vez se podrían ampliar, en el futuro, las excavaciones a lo largo de la cara sur externa del E8; es decir, por cada lado de nuestro cateo, con el fin de verificar la existencia de otros hallazgos, tal vez más intactos.

\section{LA ENTRADA AL COMPLEJO E8 (UNIDAD 122)}

Se excavó un rectángulo $4 \mathrm{~m} \times 7 \mathrm{~m}$, es decir, $28 \mathrm{~m}^{2}$ en la zona noroeste del patio, donde una depresión en los muros hace sospechar que hay una entrada 
(ver Figura 3). Se decidió excavar en este lugar con fines de determinar la presencia de un vano de acceso al patio del E8 y recolectar evidencias sobre la secuencia y la índole de la ocupación en este lugar (ver Figura 16).

- Capa superficial: Superficie en declive hacia el noroeste conformada por arena eólica gris suelta mezclada con escaso material conformado por palos, tiestos y restos malacológicos de $5 \mathrm{~cm}$ a $10 \mathrm{~cm}$ de espesor. - Capa 1: Derrumbe de adobes enteros y fragmentados, más ancho al pie de las dos caras del muro del patio; adobes $(50 \mathrm{~cm} \times 30$; $\mathrm{cm} \times 10 \mathrm{~cm}$ de alto) mezclados con escasos tiestos diagnósticos y no diagnósticos, retazos de textil, regular cantidad de material orgánico: cañas, maní, algodón, pelo, gran cantidad de hojas de choclo y restos malacológicos. Una vez retirada la capa se evidenció la cara externa e interna del muro, se constató la cabecera del muro suroeste rota y rellenada con adobes rotos mezclados con material malacológico.

En el centro de la cuadrícula se observó el ingreso sellado con adobes enteros paralelípidos reutilizados, fragmentados, y algunas lajas de forma cúbica de $(20 \times 20 \times 15 \mathrm{~cm}$ aproximadamente), amontonados, sin argamasa. Una vez retirado este sello, se aprecia el vano que tiene 2,37 $\mathrm{m}$ de largo y 1,60 $\mathrm{m}$ de ancho, en intramuros y se eleva a $20 \mathrm{~cm}$ encima del piso, como si fuera un umbral. La entrada tiene bases de lajas de forma paralelepípedas, con un adobe intrusivo y unos faltantes.

- Capa 2: Arena gris suelta de textura media. Presenta compactaciones de tierra con material orgánico y restos vegetales, cañas, cáscaras de maní, mazorcas de maíz, semillas de zapallo, carbón, material 
malacológico, trenzado en piel de animal, tiestos llanos y diagnósticos (asas). Esta capa rompió el piso 1 asociado a la entrada en el extremo noroeste del muro suroeste, en que se observa una pequeña fracción $10 \mathrm{~cm}$ de largo del revoque, un poste de madera ubicado cerca a la entrada del patio de $20 \mathrm{~cm}$ de diámetro que corta el piso desde la capa 2.

- Capa 3 (piso 1): Presente al interior del patio, el piso fue preparado con tierra arcillosa gris, cuya textura muestra ser compacta y es de 2 $\mathrm{cm}$ a $3 \mathrm{~cm}$ de espesor, presentó pequeñas depresiones de desgaste, se conserva $15 \%$ en un espacio de $1,80 \mathrm{~m} \mathrm{x} 80 \mathrm{~cm}$, espacio en el que se halló un hoyo de un posible poste y huellas de zanjas para muros de quincha que ingresan hasta la capa 5.

-Capa 3B: Al oeste del ingreso -corredor-, el piso beige de $8 \mathrm{~cm}$ a $10 \mathrm{~cm}$ de espesor, se encontró más intacto el estrato por debajo del piso que presentó inclusiones de cascajo gris, cantos rodados y arena marrón mezclados con tiestos llanos y diagnósticos, material malacológico, maní, cañas y carbón.

-Capa 4: Adentro del patio, se trata de tierra beige con cascajo de piedras semicompacta a compacta, de $10 \mathrm{~cm}$ a $12 \mathrm{~cm}$. de espesor, que ha servido de base para sentar el piso de la capa superior. Contiene regular cantidad de fragmentos de cerámica (diagnóstica y no diagnóstica), fragmentos textiles, maíz, maní, lúcuma, y restos malacológicos.

Por el lado externo del vano -corredor-, la capa se compone de arena marrón oscuro, de textura media con inclusiones de cascajo gris y restos malacológicos. Estrato en el que se aprecian piedras de cara trabajadas de $30 \mathrm{~cm} \times 20 \mathrm{~cm}$, las mismas que pudieron 
corresponder a la cabecera de un muro anterior de $47 \mathrm{~cm}$ de ancho por $7 \mathrm{~m}$ de largo. Este fue nivelado y sobre el cual se sentó el piso 1 relacionado al mismo nivel que el piso 1 del recinto U102.

-Capa 5: Superficie irregular con presencia de quema, estrato conformado por tierra arcillosa beige a gris, con presencia de lentes de arena asociado a escaso material cultural, capa que alcanzó de 3 $\mathrm{cm}$ a $6 \mathrm{~cm}$ de espesor. Sobre esta capa se asentó el muro suroeste, que define el patio del E8, muro asociado al piso 1 de ingreso. Por lo tanto, parece que la capa 5 fue una capa de preparación para la construcción del edificio.

-Capa 6: La superficie presentó áreas de quema de $20 \mathrm{~cm}$ a $30 \mathrm{~cm}$ de diámetro asociadas con carbón, tierra quemada y restos vegetales (maíz, lúcuma, camote, mate) y material malacológico y óseo. El interior estuvo conformado por arena gris suelta de textura fina en $60 \mathrm{~cm}$ de espesor.

-Capa 7 (piso 2): De superficie homogénea, con pequeñas depresiones, preparada con tierra arcillosa, beige, compacta, de textura porosa, de $2 \mathrm{~cm}$ a $4 \mathrm{~cm}$ de espesor. Se extiende por toda el área excavada y pasa por debajo del muro. No evidenció material asociado.

- Capa 8: Relleno semicompacto de arena beige de $28 \mathrm{~cm}$ de espesor, sin material asociado.

- Capa 9 (piso 3): Superficie homogénea preparada con tierra arcillosa, gris, compacta, de textura fina de unos $3 \mathrm{~cm}$ a $4 \mathrm{~cm}$ de espesor. 
- Capa 10: Arena parda, muy limpia, semicompacta a compacta, de 1,30 $\mathrm{m}$ de espesor. Se observó una ligera variación a los $0,95 \mathrm{~m}$ de profundidad compuesta por arena beige más fina.

- Capa 11 (piso 4): Superficie semiporosa preparada con tierra arcillosa gris que cubre la roca madre. (Ver Figura 17)

\subsection{COMENTARIOS E INTERPRETACIÓN RESPECTO A LAS EXCAVACIONES EN LA ENTRADA AL COMPLEJO E8}

Se pueden distinguir seis etapas en la estratigrafía puesta en evidencia:
a) Piso antiguo (capa 11).
b) Relleno y nuevo piso (capas 10 y 9 ).
c) Relleno y nuevo piso (capas 8 y 7).
d) Fundación y ocupación del patio del E8 (capas 6 a 3, muro suroeste y vano con umbral de piedras).
e) Uso como lugar para viviendas de quincha (capa 2).
f) Abandono definitivo (capas 1 y 0 ).

Las tres primeras etapas son difíciles de comentar, considerando el área reducida de la excavación y la casi ausencia de restos culturales. Lo más probable es que estén asociadas con el muro antiguo que se detectó afuera del vano en la capa 4. La etapa 5 es probablemente postconquista, pues es el tipo de reocupación algo informal que se ha observado en muchas otras partes del sitio para este periodo. 


\section{COMENTARIOS E INTERPRETACIONES GENERALES RESPECTO}

\section{A LAS EXCAVACIONES EN EL E8}

Se pudieron distinguir tres fases principales. Estas son las que siguen: (a) las ocupaciones pre E8, (b) la fundación y uso del complejo, (c) y abandono.

\subsection{OCUPACIONES PRE E8}

En la U101, las tres primeras fases no contenían material diagnóstico y pueden pertenecer tanto al Horizonte Tardío como a épocas anteriores. Se trata de una sucesión de pisos y arquitectura sin caracterización específica en términos de índole de la ocupación. Luego se construyó el depósito cortando un muro más antiguo y colocando una ofrenda de maíz y ají (H7, capa 8) que pudo reflejar el tipo de uso para este depósito. Se debe mencionar que se encontró un contexto similar en la pirámide con rampa N. 3, es decir, una ofrenda de maíz en una capa de relleno constructivo en la esquina de un depósito en la Plaza II (cf. Eeckhout y Farfán 2000).

En la U121 y 122, las primeras etapas son difíciles de comentar. Esto se debe al área reducida de la excavación y la casi ausencia de restos culturales.

\subsection{FundACIÓN Y USO}

Tanto las características del material constructivo como de las evidencias culturales indican que la estructura corresponde al periodo Horizonte Tardío. Sobre la base de lo expuesto en la U122, se puede decir que la construcción del E8 es el fruto de un solo esfuerzo, el cual ha sido tremendo. Si se considera el espesor del relleno de la capa 6 (60 $\mathrm{cm}$ de arena seleccionada) y se proyecta al conjunto de la superficie del edificio y su patio, alcanzaría 
unos 3000 metros cúbicos solo de arena. La densidad másica de la arena seca varía según su granulometría y composición, desde 1,7 a 1,9 kg por litro $\left(1850 \mathrm{~kg}\right.$ en promedio por $\mathrm{m}^{3}$ ). Son pues $5550000 \mathrm{~kg}$ de arena que se tuvo que transportar, lo que representa, si tomamos una distancia de 250 $\mathrm{m}$ hacia el río (sería todavía más, hasta la playa), unos 4363 hombre/días, ${ }^{1}$ sea por ejemplo 100 hombres trabajando durante 1 mes y medio, solo para esta etapa.

Se nota también en el sistema constructivo que los depósitos están unidos por un solo muro divisorio en dos hileras. Estos se prolongan de este a oeste.

Al respecto, las evidencias de cateos en la Unidad 102 por debajo del piso 1 sugieren que varios muros más tempranos conformaban una estructura más antigua, cuyo diseño, tamaño y ubicación es comparable al recinto más tardío. Asimismo, en la U106, una línea de $15 \mathrm{~cm}$ de ancho corre a lo largo del muro noreste, lo que sugiere lo mismo para las Unidades (U102 y U104). Hay un muro temprano que corresponde a una etapa anterior de similar diseño general. Se trata verosímilmente de una etapa preliminar del sistema constructivo.

Asimismo, se pudo evidenciar en las excavaciones de la estructura U99 que el muro suroeste, es decir, por el lado de los depósitos, en este caso de la unidad (U112), descansa sobre otro muro más ancho, al igual de lo que se pudo observar en los depósitos U102 al 108, y que corre, probablemente, a lo largo del lado norte de los depósitos, es decir, hasta la unidad (U120). Lo mismo se pudo observar en la U101, en la otra hilera de depósitos. Por lo

1 Medida empleada en arqueología experimental y termodinámica. Se refiere a la cantidad de trabajo (de tal o cual tarea) que puede llevar un hombre en un día. En este caso, se calculó que desplazar el volumen de arena para realizar el relleno de la plaza necesito esta cantidad de hombre/días. 
tanto, deja suponer que estos muros anchos inferiores tenían como función soportar y dar asiento a los muros más delgados del E8.

La capa 3 piso 1 y enlucido de los depósitos fueron preparados al mismo tiempo y el piso 1 fue cubierto de inmediato por la capa $2 \mathrm{~B}$. Es interesante destacar la presencia en varias unidades de ofrendas de mullu unidades (U99, 101, 102,105, 109), y fragmentos de mullu, así como valvas enteras en las unidades (U104, 107,113), lo cual corresponde, probablemente, a alguna actividad ritual que se llevó a cabo justo antes de colocar la capa 2B de arena de playa que contiene el maíz. Por lo tanto, se pueden considerar estos hallazgos como ofrendas de inauguración, tal vez con fines propiciatorias para las buenas cosechas, siendo el mullu tradicionalmente vinculado con el agua, las lluvias, etc. Si bien compartimos que se trata de una actividad ritual y fines propiciatorios, como lo indican y lo hacen las crónicas y lo subraya Murra, se sugiere que estas ofrendas fueron colocadas en hoyos o sobre la superficie para el uso del espacio depósito- y el tipo de materia que posteriormente sería colocado, sea maíz $\mathrm{u}$ otra especie. El cubrimiento por arena limpia bien pudo ser para mantener en buen estado la materia prima o cubrir para su abandono. En términos taxonómicos, llama la atención el hecho de que a pesar de haber sido cubierto inmediatamente, luego de su construcción e inauguración por una capa de medio metro de arena fina, los pisos muestran huellas de desgaste. Estas huellas por lo general toman la forma de depresiones redondas o irregulares de poca profundidad. Podrían, pues, corresponder a actividades rituales que se llevaron al mismo tiempo que las ofrendas de mullu. Es posible también que estas depresiones fueran por un mayor uso de espacio, para arrojar o colocar la materia prima, porque el hecho de ofrendar nos parece de un 
solo momento, que es cuando colocaron el mullu, pero no dejaron huellas observables (por ejemplo líquidos echados, entre otros).

La capa 2B en los depósitos es un relleno ex profeso de arena de playa para conservar los alimentos en condiciones de variaciones mínimas en términos de temperatura y humedad, referido anteriormente, así como para protegerlos de los animales como los roedores, los cuales no pueden cavar túneles en materiales tan sueltos. Se notan diferentes tipos de maíz mezclados en los mismos depósitos. Estas diferencias son tanto en dimensiones como en el color de los granos (amarillos y oscuros, tipo «maíz morado»). El límite superior de la capa corresponde con el límite del enlucido en buen estado de conservación, lo cual indicaría que fue cubierto desde un inicio y demuestra una correspondencia temporal entre la colocación de la arena y el uso de los recintos.

El espesor muy fino de la capa $2 \mathrm{~B}$ y el estado de desgaste del piso en los depósitos U114, 116, 118 dejan sospechar que no contenían nada al momento de abandono, lo que explica el mal estado de conservación con respecto a los demás depósitos del conjunto. Igual para el U120, el cual muestra, sin embargo, restos de ají.

Asimismo, destaca la estratigrafía particular de varios recintos, especialmente la unidad U112, que al parecer sirvió para almacenar mates, los cuales tal vez sirvieron para los banquetes y festines organizados en el patio del edificio. La ubicación de la unidad U112 es bastante específica, pues se encuentra justo detrás del cuarto del Quipucamayoc, el supuesto funcionario principal encargado del edificio E8 (U99). Frente a la U99 en el patio, el conjunto de evidencias deja pensar que no solo se consumió en este lugar, sino también se manipularon los mates hallados enteros. 
El U110 también es especial, por no contener absolutamente ninguna evidencia de uso, sino solo unos pedazos de cerámica decorada y un mate. Está ubicado justo al lado el U112, cerca al cuarto del Quipucamayoc. Podemos pensar que este recinto estuvo vinculado con el papel de este funcionario del Estado, y contenía otros implementos para banquetes. Los fragmentos decorados corresponden a una vasija globular que podría haber sido para chicha, y el mate contenía mazorcas. Esto podría indicar que en la unidad U110 se conservaban jarras de chicha para el uso del funcionario y las necesidades de su oficio. Cuando se abandonó el lugar y se vaciaron los depósitos no se dejó casi ninguna huella, pues se llevaron los recipientes, salvo tal vez uno que se halló roto, mientras donde se conservó maíz, quedaron mazorcas y granos en la capa de arena inferior.

Entre los deberes del funcionario estatal podía, pues, figurar la organización de banquetes y festines, marcas recurrentes de la reciprocidad andina en el ejercicio de la autoridad. Sería perfectamente lógico imaginar este tipo de relación en un ámbito clave como un conjunto de depósitos donde se almacenaba probablemente el producto de la mita. El patio frente al cuarto y los depósitos para lo que pudieron servir, entre otros, para estos fines. La cantidad de mates encontrados en la unidad (U112) sobrepasa de lejos lo necesario para la vida diaria de un solo funcionario, pero podría caber para una cena de varias docenas de personas. El conjunto de evidencias, pues, sugiere que la unidad (U112) servía de «armario» para la vajilla que se usaba durante las fiestas y comidas organizadas en el E8 por el poder imperial, representado a nivel local por el Quipucamayoc, cuya oficina se ubicaba en la unidad U99.

El hallazgo de dos quipus en la capa superior, probablemente, procedente de la parte interna de la estructura U99 saqueada, refuerza la 
idea de que se trata de una unidad de gestión del contenido, en su mayoría de origen vegetal, de los depósitos. Dentro de la capa 3 al noreste de la cuadrícula se encontró el Hallazgo 20: dos ovillos de hilo beige, marrón y crema. Hay cabellos incrustados en los ovillos. Es posible de que se trate de la materia prima para fabricar las cuerdas de los quipus como los encontrados en la parte superior de la estratigrafía, ya que los hilos son muy similares.

\subsection{Abandono}

En los depósitos, la capa 2A corresponde al periodo de abandono del lugar con acción destructora de la erosión eólica que afectó las partes expuestas de los muros. Cabe resaltar que hay dos tipos de derrumbe que pueden distinguirse y diferenciarse en la zona de los depósitos. El primero: colapso del muro alto que conforma el límite sureño del E8 y, por lo tanto, el lado sur de los diez depósitos con números impares en nuestra nomenclatura (U101, 103, 105, etc., hasta U119). En este lugar, se aprecia la mayor cantidad de derrumbe (hasta 1,5 $\mathrm{m}$ de espesor) y los bloques más grandes, por el tamaño mayor que tenía el muro. Este muro ha caído de manera dispersa, con bloques encima unos de otros, en sentido norte a sur en dirección al interior de los depósitos, lo que evidencia un colapso gradual, incluido en varias etapas, separadas por cierto lapso de tiempo. El segundo tipo de derrumbe corresponde a un colapso casi completo del muro en un solo momento, probablemente, debido a un terremoto fuerte. En este caso, la pared casi completa ha caído en el depósito, y se puede apreciar, por ejemplo, en el muro divisorio entre la U102 y la U104, en donde dicho muro ha caído casi por completo adentro del recinto U104. El espesor de este tipo de derrumbe nunca supera $1 \mathrm{~m}$. 
Estos dos tipos de derrumbe tal vez se explican por el tamaño original de los muros, pues el muro sureño del E8 es mucho más ancho y sostenido por un relleno muy profundo en su cara externa, mientras los muros divisorios de los depósitos son más delgados y sin sostén. Por lo tanto, el muro grande resistió mejor a los terremotos.

Cerca de la entrada en la U122 las viviendas de quincha son, probablemente, postconquista. Se deduce esto pues es el tipo de reocupación algo informal que se ha observado en muchas otras partes del sitio para este periodo.

Al parecer la zona de los depósitos U119-120, la más cercana al asentamiento humano moderno Julio C. Tello, sirvió de basural antes de que se cerrara la zona monumental del sitio. El lugar se cerró en los años 70.

\section{CONCLUSIONES}

¿Qué podemos concluir de estos datos respecto al tema de la logística económica del Imperio Inca? Durante el periodo Intermedio Tardío los almacenes estuvieron asociados a las pirámides con rampa, las cuales no han sido usadas de manera simultánea. Al contrario, todas las facilidades de almacenamiento han funcionado conjuntamente en el periodo Horizonte Tardío. Por lo tanto, resulta algo artificial comparar, por ejemplo, la capacidad de almacenamiento global del sitio antes y durante el Imperio Inca. Sin embargo, dicha comparación se revela muy interesante y la llevamos a cabo en esta investigación para fines heurísticos. Si sumamos las capacidades de todas las qollqas usadas durante el periodo Intermedio Tardío, llegamos a unos $9270 \mathrm{~m}^{3}$, mientras el total para el Horizonte Tardío es de $7830 \mathrm{~m}^{3}$ (Ver Figura 21). 
Considerando lo que se ha dicho antes, se pueden hacer varias deducciones al respecto. A continuación se explicará cada una de ellas.

La capacidad de almacenamiento global es casi igual, esto sugiere que en realidad ha aumentado de manera relativa en el Horizonte Tardío pues se concentra sobre un periodo más corto (60 años en relación a 120 años).

La distribución de las qollqas ha cambiado por completo, y es muy instructiva respecto al manejo del sitio y de la región por parte de los Incas. En efecto, los edificios y sectores en los cuales se encuentran estos depósitos están estrechamente vinculados con los aspectos ceremoniales y religiosos. Por una parte se encuentran el Templo del Sol, el Acllahuasi, los edificios A1-A2 y la Pirámide 13, y con la gestión estatal, por otra parte el Edificio E8 y la Pirámide 10-Tauri Chumpi. Es lógico suponer que los depósitos asociados al Templo del Sol estaban dedicados al culto solar, y que el Acllahuasi, como bien se sabe, tenía también sus recursos propios para las acllas y el culto lunar (Tello 2009). El edificio A1-A2 y la P13 se ubican en los lados de la Plaza de los Peregrinos, la cual fue construida por los Incas para acoger las grandes romerías que organizaron a través del Imperio para celebrar el Oráculo de Pachacamac (Eeckhout 2008). Se sabe que los peregrinos llevaban muchas ofrendas, y que también se necesitaron muchas infraestructuras para acogerlos. La cantidad de qollqas en el A1-A2 corresponde perfectamente con estas necesidades, mientras la Pirámide 13, estratégicamente ubicada cerca a la entrada de la Plaza, y con varios accesos a esta, quizás albergó a un sacerdote importante. Recordamos al respecto que las crónicas mencionan dos funcionarios supremos en Pachacamac durante el Incanato: el gran sacerdote del Templo, y el gobernador o tucrikuk (Eeckhout 1998). Este último ha sido identificado con Tauri Chumpi, y por esto se le ha atribuido el nombre de Palacio de Tauri 
Chumpi a la estructura excavada por Alberto Bueno en la parte norte del sitio (Bueno 1974/75). Todos los autores están de acuerdo con la atribución de este edificio al Horizonte Tardío, siendo, probablemente, la residencia del jefe secular del sitio en ese entonces. Esto nos lleva, naturalmente, a la parte de las qollqas dedicadas a la gestión estatal, las cuales se ubican con justa razón en el mismo palacio del tukrikuk (para su uso propio, el manejo de su personal, las necesidades de su oficio, etc.) y en el Edificio E8, ubicado en el mismo barrio del sitio, probablemente, cerca de una entrada hoy desaparecida. Allí se recibía el producto de las chacras y otros recursos locales de los cuales el estado inca se había apoderado. Es interesante remarcar que los depósitos del E8 están asociados a un gran patio, el cual pues tal vez servía para acoger a la gente durante los banquetes y ceremonias de redistribución que forman parte del ejercicio del poder inca (Bray 2003).

Quizá, también, este gran patio podía albergar a las caravanas de camélidos que servían para transportar los bienes hasta el sitio. No hay duda que estas hipótesis se podrían verificar mientras se realicen excavaciones más extendidas en el patio.

Recordamos que aparte de los depósitos, la presencia de funcionarios oficiales y los accesos al Qapaq Ñan son dos de otros rasgos recurrentes compartidos por los asentamientos estatales. Esto tiene confirmación en los datos arqueológicos procedentes de Pachacamac, y los nuevos hallazgos presentados aquí comprueban el hecho y nos ayudan en entender la especificidad de la estrategia inca en la zona.

En efecto, los Incas construyen sus propias facilidades administrativas y de gestión, pero adaptándose al contexto local, pues por un lado adoptan las técnicas constructivas y el diseño arquitectónico tradicional en Pachacamac, pero por otro lado construyen estructuras específicas para la gestión, es decir, aisladas y separadas de las residencias de los curacas. En 
este sentido, los Incas son muy diferentes de los Ychsmas. El dispositivo inca manifiesta también un manejo global del sitio y de los recursos regionales, posiblemente, con enfoque en los aspectos ceremoniales, tal como la cita de Pizarro lo sugiere: «No tributaban al Cuzco sino a la mezquita» (1872).

Esta peculiaridad tal vez explica por qué son tan reducidas, a fin de cuenta, las capacidades de almacenamiento en el sitio. Es cierto que la mayor parte de Pachacamac, es decir, la tercera muralla, casi no ha sido excavada. Sin embargo, los pocos trabajos que se han realizados y publicados no atestiguan la presencia de qollqas en este lugar, sino de núcleos de actividad y residencia precaria (Malaga Villa 2008) y entierros del Horizonte Tardío y Periodo Colonial temprano (Uhle 1903:62-70). Hasta mayor información, tenemos pues que considerar que los depósitos incas se concentraron en la primera y segunda muralla, es decir, la parte monumental del sitio, y específicamente en los sectores vinculados con las actividades ceremoniales.

En este sentido, no se puede considerar Pachacamac como un asentamiento estatal del tipo "tambo", usado para abastecer los ejércitos imperiales en marcha y, por lo tanto, diseñado para almacenar enormes cantidades de bienes. Tal fue, probablemente, el caso en Huánuco Pampa, Hatun Xauxa o Pumpu, cuya capacidad de almacenamiento es 5 a 10 veces más grande que Pachacamac. Este último parece pues dirigido principalmente a las funciones religiosas (y especialmente lo que concierne a las romerías) y administrativas (el palacio de Tauri Chumpi). El Edificio E8 puede haber jugado un papel híbrido, es decir, a la vez, un instrumento de gestión local, como lo hemos descrito líneas arriba, pero también incluyendo, por su misma localización y diseño, la función de tambo para los funcionarios incas en tránsito y los chasquis. En nuestra opinión, los Incas invirtieron más en facilidades cultistas que en la construcción de qollqas a gran escala por dos 
razones. En primer lugar, la costa central y la región Ychsma ya constaban con una red muy desarrollada y jerarquizada de sitios equipados con depósitos para el manejo y control de los recursos del Señorío (Eeckhout, ed. 2004; Eeckhout 2009). No había pues necesidad para los Incas de construir más, sino simplemente aprovechar de lo existente. Tal contexto no fue igual en las partes de la sierra donde establecieron los grandes sitios como Pumpu, Hatun Xauxa o Huánuco Pampa, los cuales concentraron las cosechas y recursos de regiones inmensas. En segundo lugar, la población del Señorío de Ychsma no fue tan numerosa, ni la productividad tan grande, como para justificar un despliegue enorme de energía en construir cientos de almacenes o estructuras para la gestión de los mismos (ver Eeckhout 2000; Feltham 1983)

Aparte de estas deducciones, que corresponden mutatis mutandis a lo que ya se observó en otras partes del Imperio, llama la atención el diseño arquitectónico del E8, el cual tiene muchas semejanzas con los depósitos incas de Tambo Viejo, valle de Acari, estudiados por Lidio Valdez (1996: 40), o el gran almacén de Quebrada de la Vaca, región de Chala, estudiado por Hermann Trimborn (1988: 129). Jaka Pelan (comunicación personal en el 2013) menciona otros sitios semejantes en la zona de Atiquipa y Chala. Valdez (1996: 41) subrayó que los depósitos de Tambo Viejo resultan de una mezcla de formas incas y locales, y que sus tamaños homogéneos facilitaron la administración contable de los productos que contenían. Los depósitos de Tambo Viejo se encontraron completamente vacíos (Valdez 1996: 41), mientras las excavaciones en Quebrada de la Vaca revelaron exclusivamente restos vegetales como semillas de algarrobo, ají, corontas de maíz y granos de quinua (Trimborn 1988:41). Proponemos pues que el E8 y los demás edificios mencionados podrían corresponder a un modelo 
arquitectónico morfo-funcional, es decir, una forma y un conjunto de elementos arquitectónicos usados de manera sistemática por los Incas cuando se trata de almacenamiento en la zona costeña. Creemos que más investigaciones en estructuras semejantes podrían permitir verificar esta hipótesis. Si se comprueba, se podría, de manera muy rápida, estimar sobre la base de los planes y levantamientos de sitios incas costeños sus capacidades de almacenamiento respectivos. Creemos que esta perspectiva abre muchas vías interesantes para un mejor entendimiento de la infraestructura imperial en las diferentes provincias de la costa.

En fin, llama la atención la estructura subyacente de la organización, notablemente los aspectos ligados al sistema decimal, la dualidad y la simbología numérica que Urton atribuye a los Incas y a los Quechuas de manera más general. Es muy obvio en el E8, que consta de dos filas de 10 depósitos y que es del Horizonte Tardío. Sin embargo, hay en Pachacamac una serie de evidencias pre Horizonte Tardío que permiten plantear, como hipótesis de trabajo, que los conceptos mencionados podrían tener raíces antiguas, de los cuales los Incas, como en muchos otros campos, constituyen el fruto más tardío y mejor conocido. Para sustentar este punto, nos referiremos al estudio de Chris Donnan (2009) respecto al uso de números y combinaciones de números entre los Moches. Sobre la base de la excavación que realizara en las tumbas en Dos Cabezas, valle de Jequetepeque, Donnan remarcó la recurrencia de los números 5, 10, 20 y 40 en diversos niveles de la organización de las tumbas, como por ejemplo entre los grupos de ofrendas y cerámica, la cantidad de adobes y palos que se usaron para cubrir las cámaras funerarias, etc. Recurrencias semejantes se pueden notar en los ajuares de las tumbas de Sipán, así como sus componentes mismos (collares de 10 piezas por ejemplo). En la Huaca Facho, valle de Lambayeque, el número 
de nichos de la fachada del templo se basa en el número 10 y combinaciones del mismo. Fuera del campo funerario pues, tenemos aplicaciones arquitectónicas de estos principios, que se pueden observar también en el sitio Wari de Azángaro, cuyas celdas octogonales están agrupadas por 20 y 40 filas. En la Pirámide 6 de Pachacamac, también observamos que los recintos hundidos adyacentes al conjunto principal constan de dos filas de cinco unidades. En otro campo, las sartas completas de ishpingo que hemos encontrado en el Templo del Mono servían en los rituales funerarios y constaban de 40 semillas, como si fuera una medida estandarizada para el intercambio (Eeckhout 2006), tal como fueron los naipes o hacha-monedas del norte de Perú y Ecuador, que siempre están unidos por múltiplos de cinco (Donnan 2009). Aunque abundan las excepciones a esta regla, seguimos a Donnan (2009:179) cuando asegura que la recurrencia de estos números y combinaciones en el área andina sugiere que «estos números tenían un significado simbólico, importante y perenne entre los nativos. Aunque su significado puede haber cambiado según las épocas y regiones siguió siendo una manera importante y fundamental de percibir y organizar el mundo de forma significante» (traducción de los autores). En Pachacamac, los Incas imponen su orden y organización, pero se imponen eficientemente porque descansa en conceptos ampliamente compartidos entre las culturas andinas que precedieron a los Incas. No se trata aquí de sugerir otra versión de «lo andino", un marco en nuestros ojos demasiado simplificador y reductor, sino más bien subrayar el sustrato muy difundido que forma parte de la especificidad de las culturas andinas.

Agradecimientos: Agradecemos al Ministerio de Cultura del Perú por haber expedido las autorizaciones de investigación en Pachacamac. El Proyecto Ychsma recibió ayuda financiera de la Université Libre de Bruselas y del 
Fonds National de la Recherche Scientifique (Bélgica). También recibimos apoyo logístico de parte del Museo de Sitio de Pachacamac y de la Embajada de Bélgica en el Perú. Queremos agradecer a todo el equipo de excavación, y especialmente a Rodolfo Monteverde Sotil, arqueólogo asistente de campo, así como a Tatiana Stellian, doctorante de la ULB en arquéobotánica. Las figuras que ilustran este ensayo han sido preparadas por Nathalie Bloch (Centre de Recherches Archéologiques de la ULB). Asumimos la total responsabilidad del contenido del presente artículo, así como de los errores que podrían existir. 


\section{BIBLIOGRAFÍA}

BRAY, Tamara L.

2003

«To Dine Splendidly: Imperial Pottery, Commensal Politics, and the Inca State $\gg$. En BRAY Tamara, L. (ed.). The Archaeology and Politics of Food and Feasting in Early States and Empires. Springer, New York, pp.93-143.

Bueno Mendoza, Alberto 1974-75

«Cajamarquilla y Pachacamac: Dos Ciudades de la Costa Central del Perú ». Boletín Bibliografico de Antropologia Americana, Vol. 37, N.46, pp. 171 211.

Donnan, Christopher D. 2009

«The Moche Use of Numbers and Number Sets». En Marcus, Joyce y Patrick Ryan Williams (eds.). Andean Civilization. A Tribute to Michael E. Moseley. Los Angeles, Cotsen Institute of Archaeology Press, UCLA, pp. 165-180.

EeCKHOUT, Peter 1993

«Le Créateur et le Devin. A propos de Pachacamac, dieu précolombien de la Côte Centrale du Pérou». Revista Española de Antropología Americana, Vol. 23, pp. 135-52. 
1998

2000

2006

2008
«Le temple de Pachacamac sous l'Empire inca». Journal de la Société des Américanistes, Vol. 84, pp. 9-44.

«Monuments, temps et pouvoir. Force de travail et structure de l'autorité à Pachacamac, côte centrale du Pérou». En Eeckhout, Peter et Jacques MALENGREAU eds.). Itinéraires belges aux Amériques. Actes du ler Colloque de la Société des Américanistes de Belgique. Civilisations, Institut de Sociologie de l'Université Libre de Bruxelles, Vol. L, N. 1-2. pp. 195-213.

«Semillas sagradas: El Ishpingo (Nectandra sp.) en Pachacamac, Costa central del Perú». En LE Secrétariat du Congrès. Change in the Andes: Origins of Social Complexity, Pastoralism and Agriculture. Acts of the XIVth UISPP Congress, University of Liege, Belgium, 2-8 September 2001. British Archaeological Reports International Series, 1524, Hadrian Books Ltd, Oxford, pp. 201210. «El santuario del Oráculo de Pachacamac y los peregrinajes a larga escala en los Andes prehispánicos». En Curatola Petrocchi Marco y Mariusz Ziolkowski. Adivinación y Oráculos en las Américas. Pontificia Universidad Católica del Perú, Fondo editorial/ Instituto Francès de Estudios Andinos, Lima, pp. 161-180. 
«Poder y jerarquias Ychsma en el Valle de Lurín». Arqueología y Sociedad, N. 19, pp. 223-240.

2012 «Absolute chronology, monumental architecture and social complexity at Pachacamac». Ponencia presentada en el Simposio Paper read at the Roundtable on the Pachacamac Sanctuary, Dumbarton Oaks. Washington. S. e.

EecKhout, Peter (ed) 2004

Arqueologia de la Costa Central del Perú en los Periodos Tardios. Instituto Francés de Estudios Andinos, N. Temático, Vol. 33, Lima.

EeckHout, Peter, y Carlos Farfán 2000

Informe Final del Proyecto Ychsma, temporada 1999. Lima: INC.

Feltham, Jane P.

The Lurin Valley, Peru: AD1000-1532. Ph. D. Diss. Institute of Archaeology, University of London, Londres.

Flores Ochoa, Jorge A., Elizabeth Kuon Arce, Roberto Samanez Argumedo, Luis Federico Barreda Murillo y Catherine Julien 2007

Cuzco del mito a la historia. Colección Arte y Tesoros del Perú. Lima: Banco de Crédito. 
Malaga Villa, Maria Bélen

2008

Arquitectura doméstica en las pampas de Pachacamac durante el Horizonte Tardio. Excavaciones en el sector $S W$ de las unidades $A-2, A-3$ y A-4. Tesis de Bachiller. Pontificia Universidad Católica del Perú, Lima.

Morris, Craig

1967

Storage in Tawantinsuyu. Unpublished Dissertation Thesis. University of Chicago.

PiZArRo, Hernando

1872 [1533]

"A Letter of Hernando Pizarro to the Royal Audience of Santo Domingo, November 1533». En Markham, C.R. (ed.). Reports on the Discovery of Peru, III. Hayklut Society, Londres, pp. 111127.

Rostworowski de Diez Canseco, María

1972

«Breve informe sobre el Señorio de Ychma o Ychima». Arqueología PUC, N. 13, pp. 37-51.

1992

Pachacamac y el Señor de los Milagros. Una Trayectoria Milenaria. Lima: Instituto de Estudios Peruanos.

STELlian, Tatiana

2012

Proyecto Ychsma-Anexo Restos botánicos Temporada 2012: marzo-mayo. S. e. 


\section{UN COMPLEJO DE ALMACENAMIENTO DEL PERIODO INCA \\ EN PACHACAMAC}

Tello, Julio C.

2009

«Arqueología de Pachacamac: Excavaciones en el Templo de la Luna y Cuarteles, 1940-1941». Cuaderno de investigación del Archivo Tello 6. Museo de Arqueología y Antropología, UNMSM, Lima.

TRIMBORN, Hermann

1988

Quebrada la Vaca. Investigaciones Arqueológicas en el Súr Medio del Perú. Lima: Fondo Editorial de la Pontificia Universidad Católica del Perú.

UHLE, Max

1903

Pachacamac. Report of The William Pepper, M.D., LL.D. Peruvian Expedition of 1896. The Dpt of Archaeology of the University of Pennsylvania, Philadelphia.

VALDEZ, Lidio

1996

«Los depósitos inka de Tambo Viejo, Acarí». 


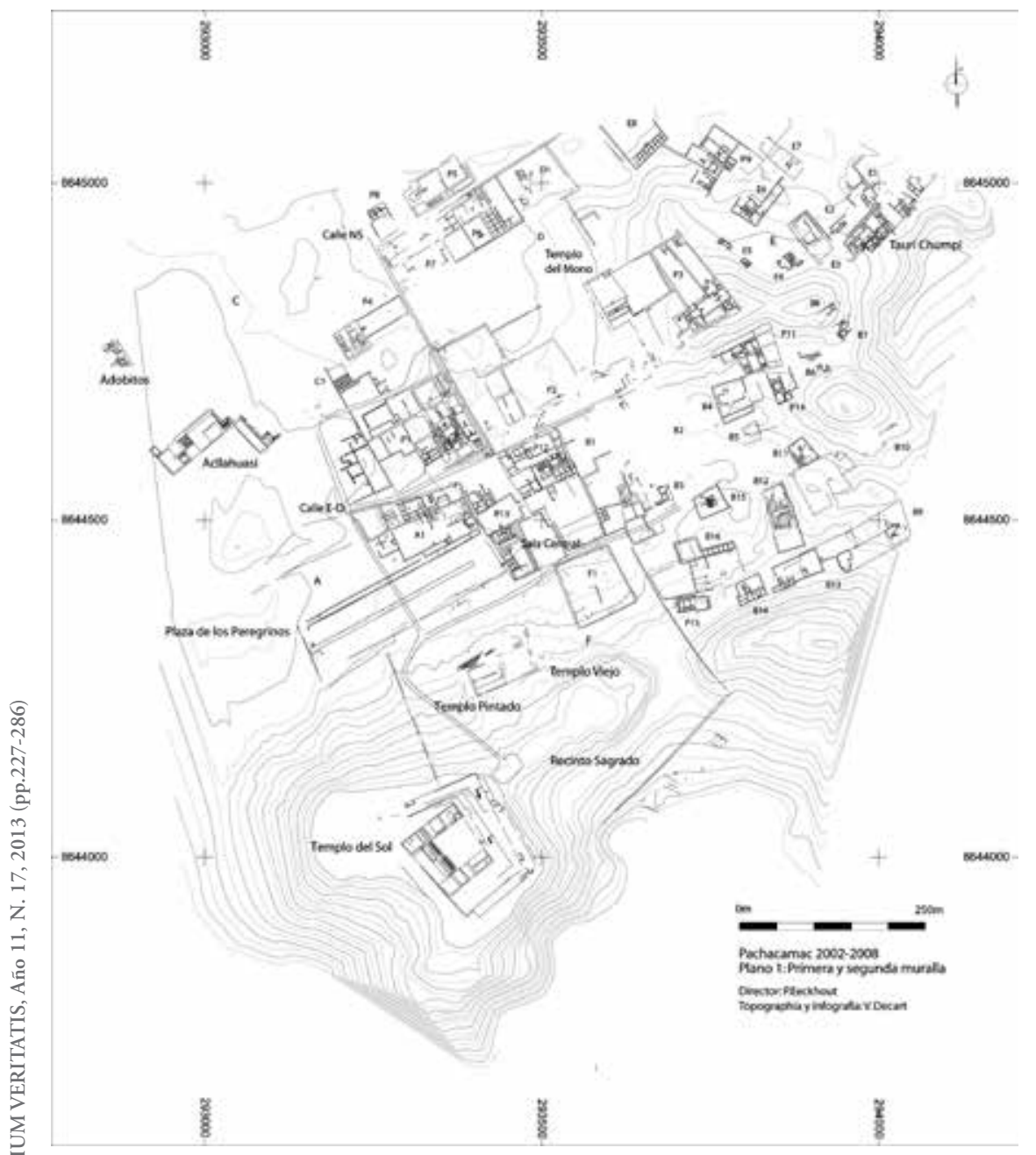

Figura 1. Mapa del sitio monumental de Pachacamac 


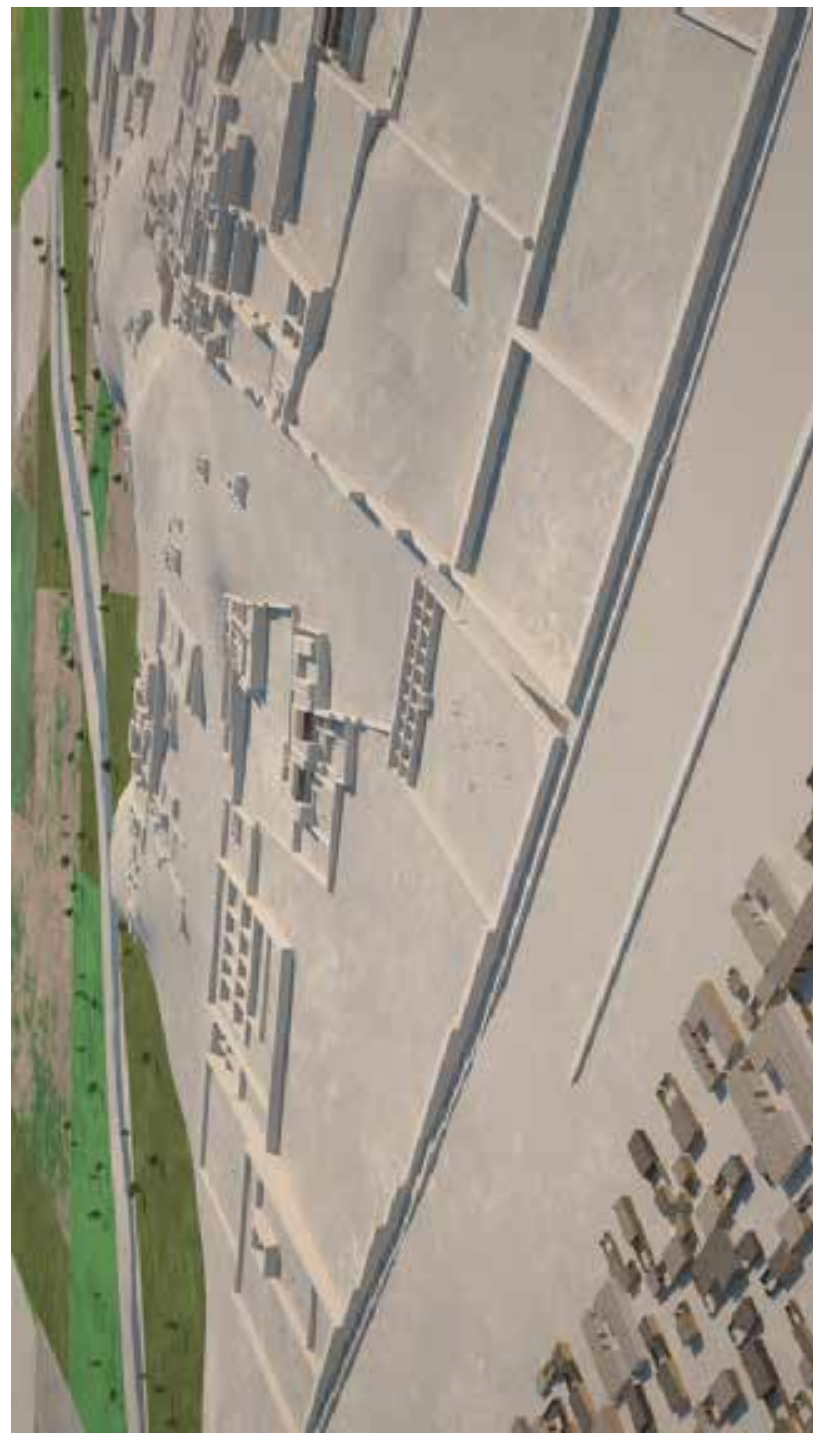






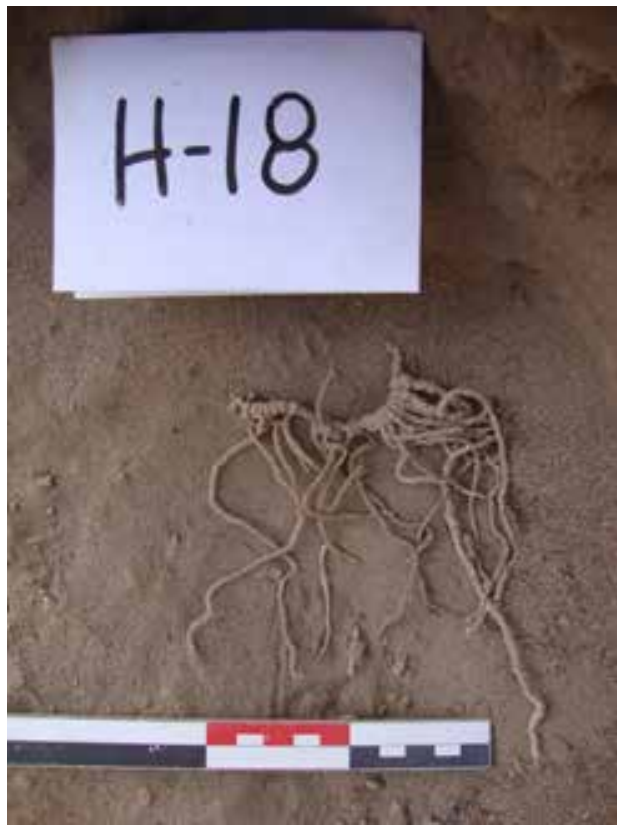

Figura 4. Hallazgo de quipus en el cuarto del Quipucamayoc (U99)

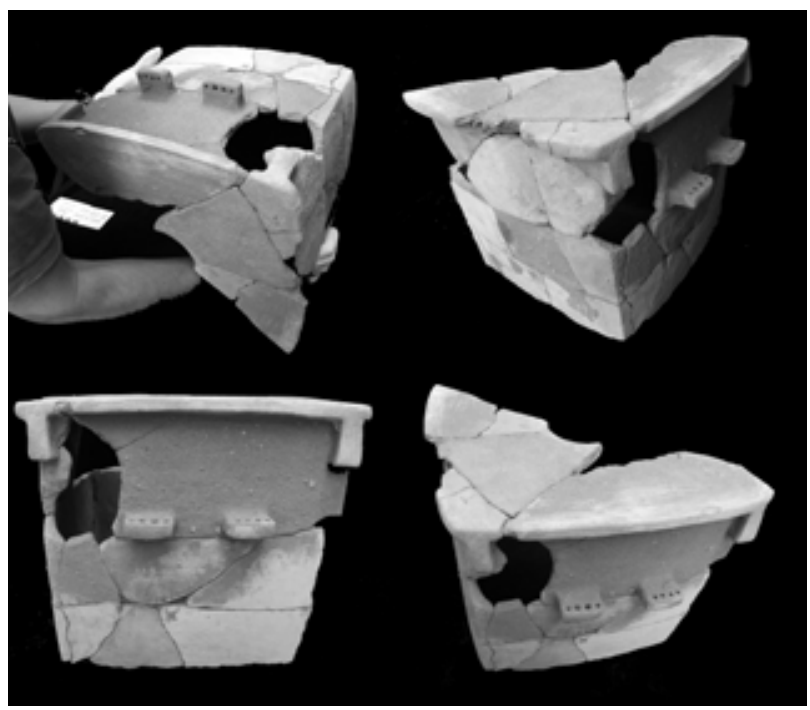

Figura 5. Vasija H24g encontrada en el cuarto del Quipucamayoc (U99) 
UN COMPLEJO DE ALMACENAMIENTO DEL PERIODO INCA

EN PACHACAMAC

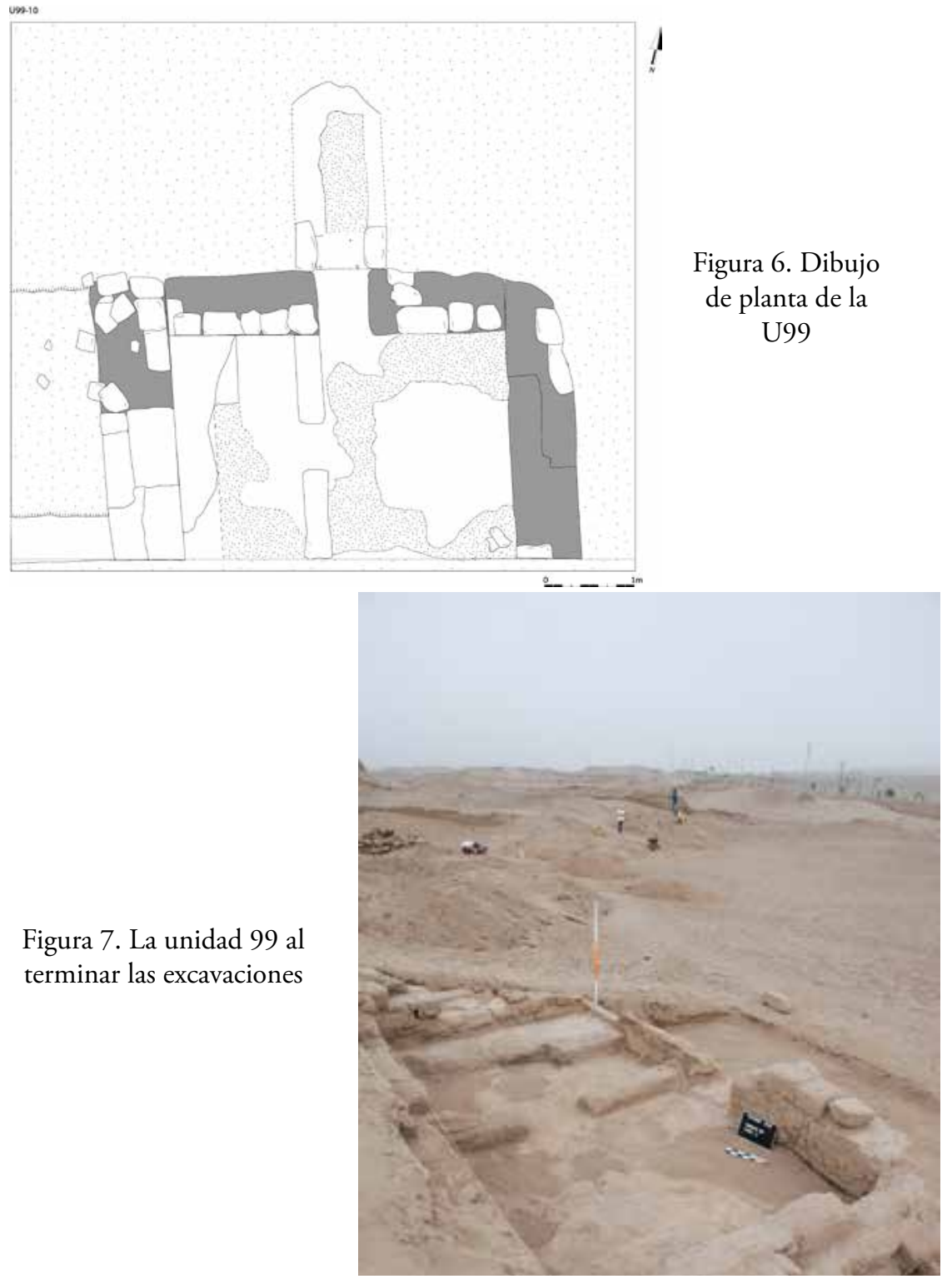

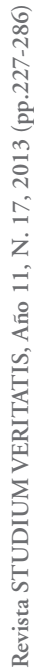




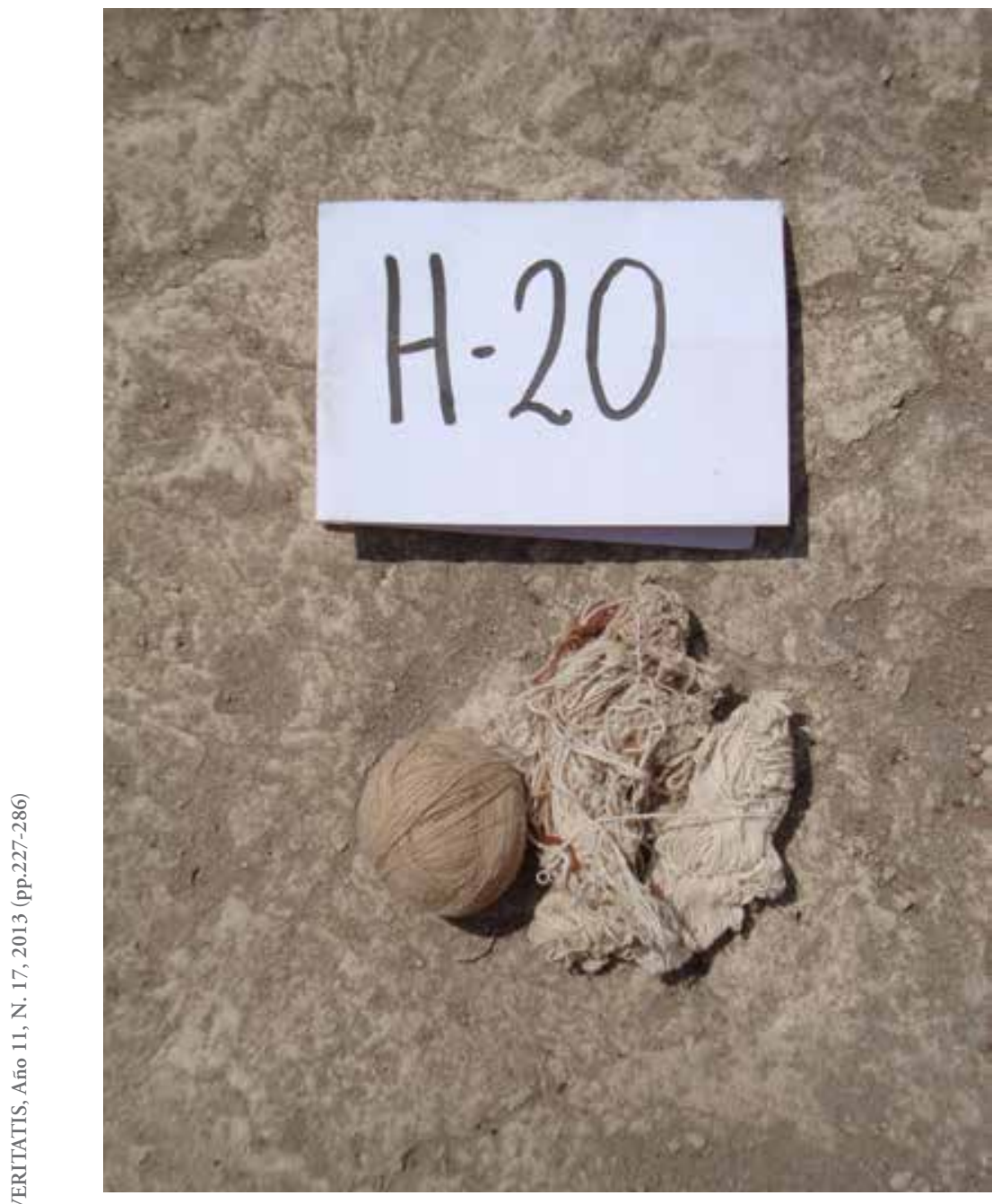

Figura 8. Hallazgo de ovillos cerca del cuarto del Quipucamayoc 


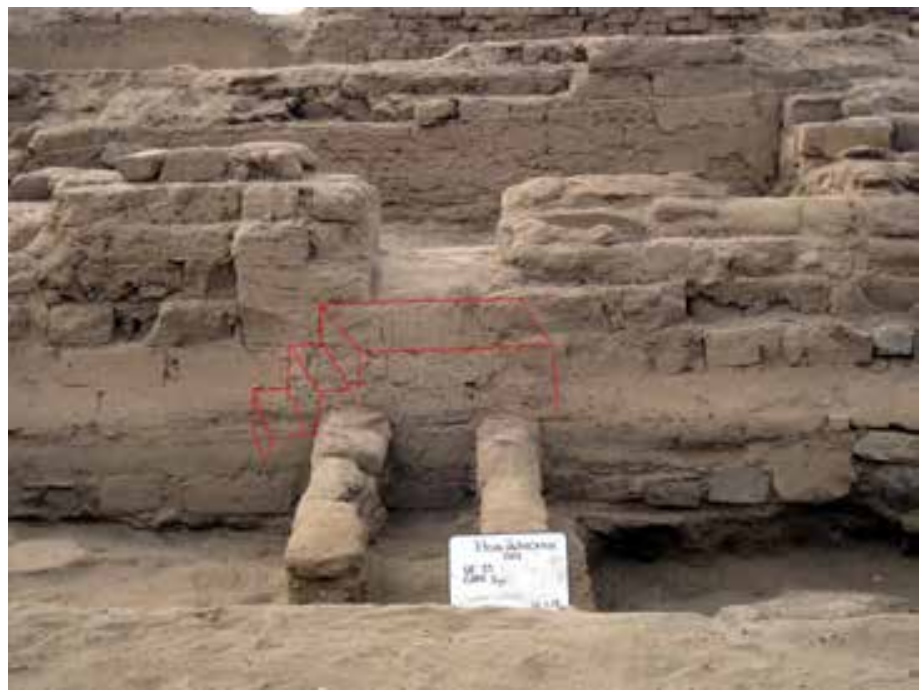

Figura 9. Proyección de la escalera lateral antigua que daba acceso a la U99

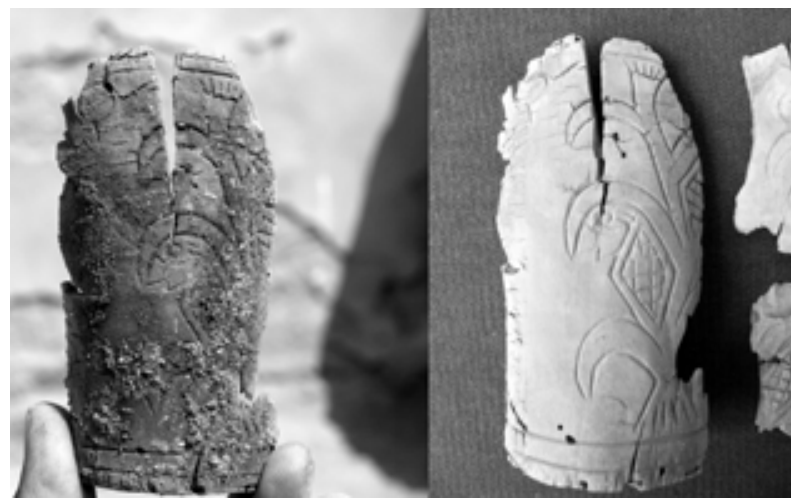

Figura 10. Vaso de madera encontrado en el cuarto del Quipucamayoc (U99) 
PETER EECKHOUT Y MILTON LUJÁN DÁVILA

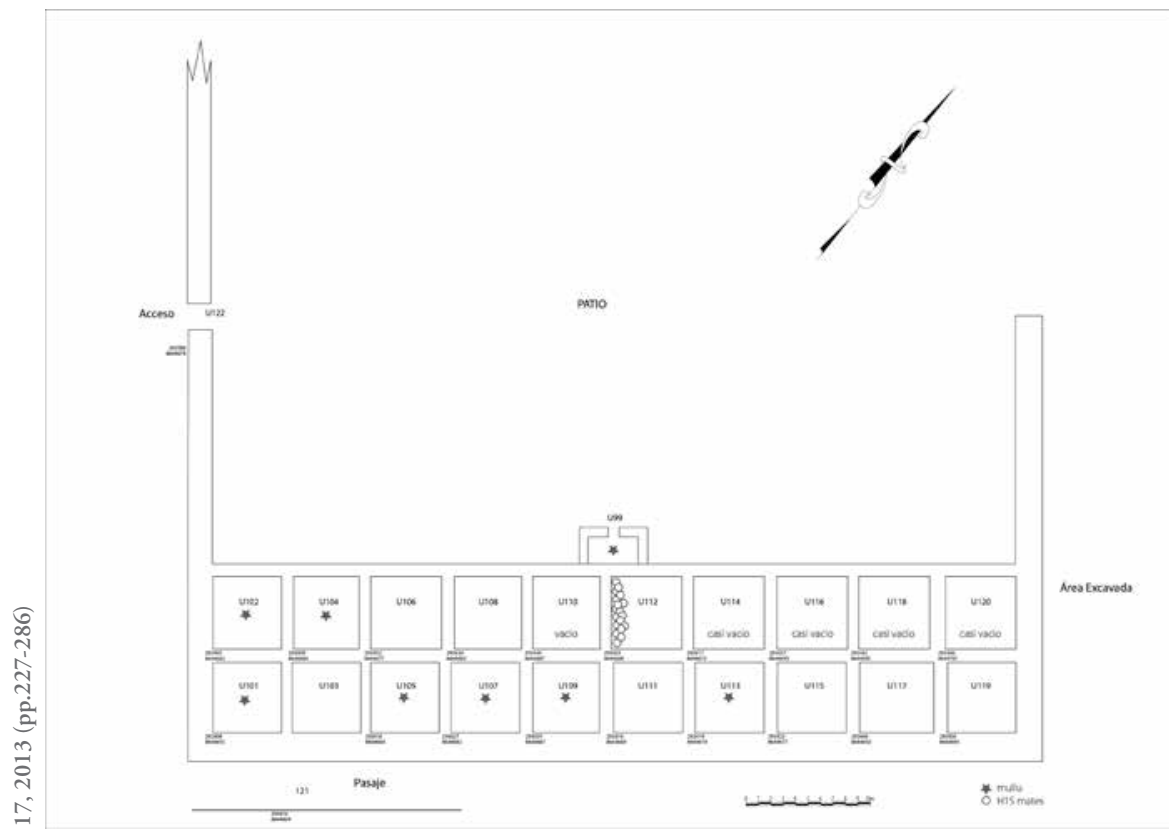

Figura 11. Ubicación de las excavaciones realizadas en el Edificio E8 


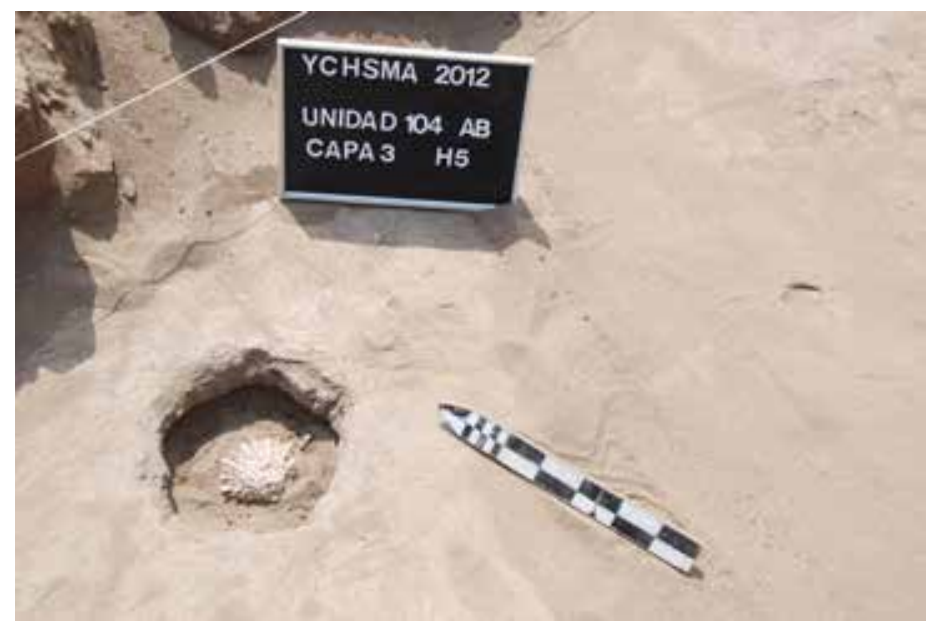

Figura 12. Uno de los hallazgos de spondylus registrados en campo

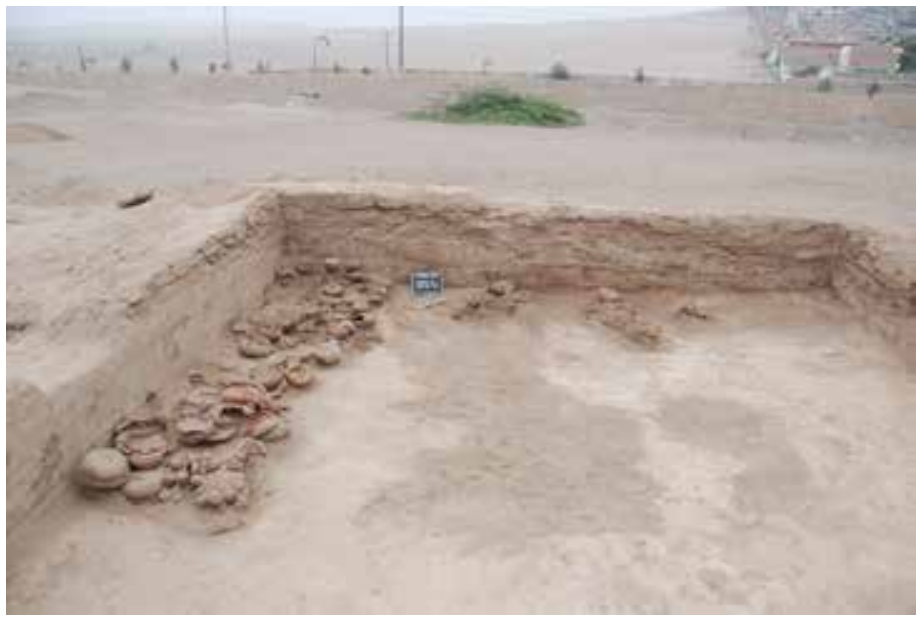

Figura 13. Hallazgos de mates en el depósito U-112 
PETER EECKHOUT Y MILTON LUJÁN DÁVILA
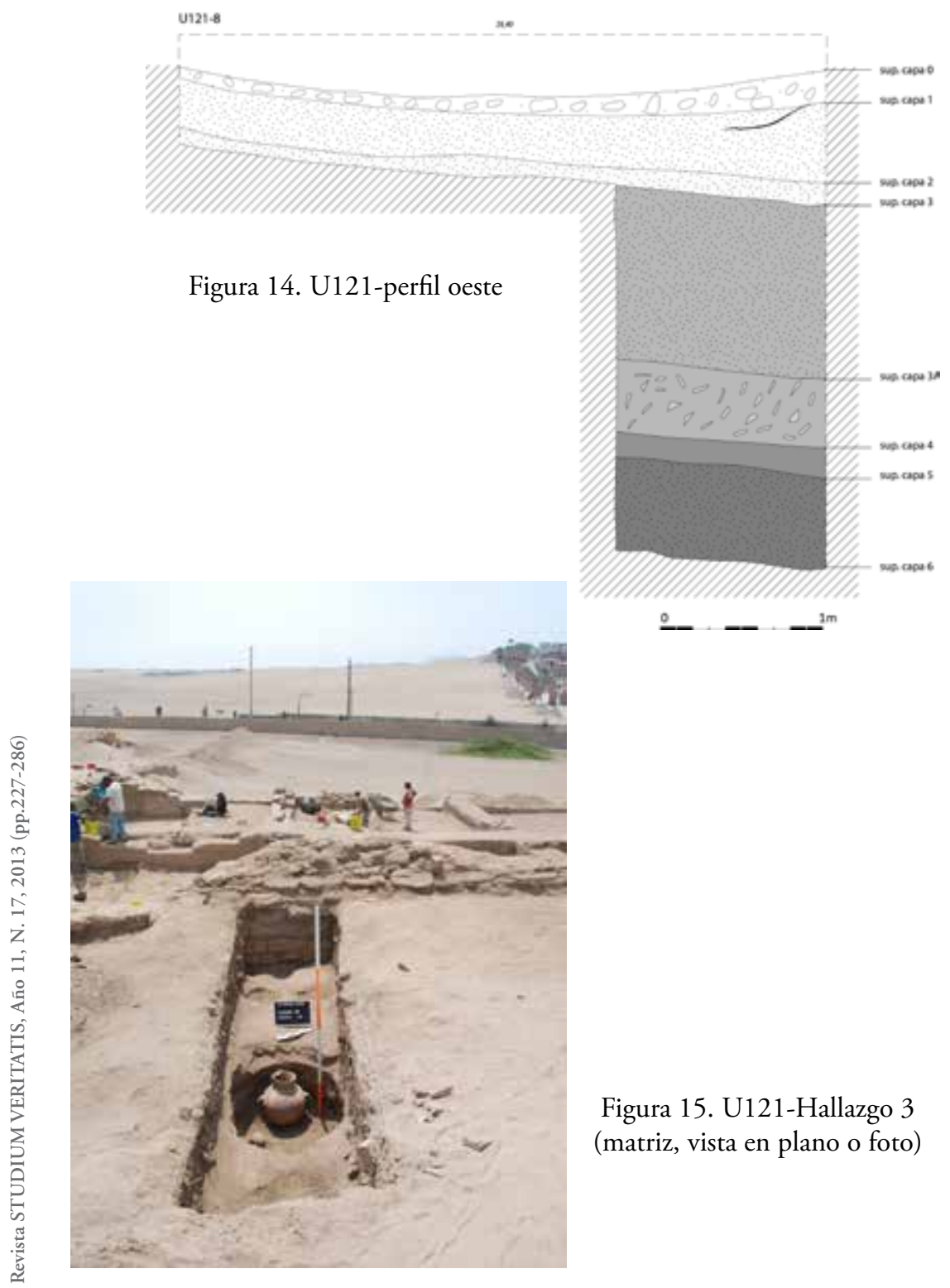

Figura 15. U121-Hallazgo 3 (matriz, vista en plano o foto) 


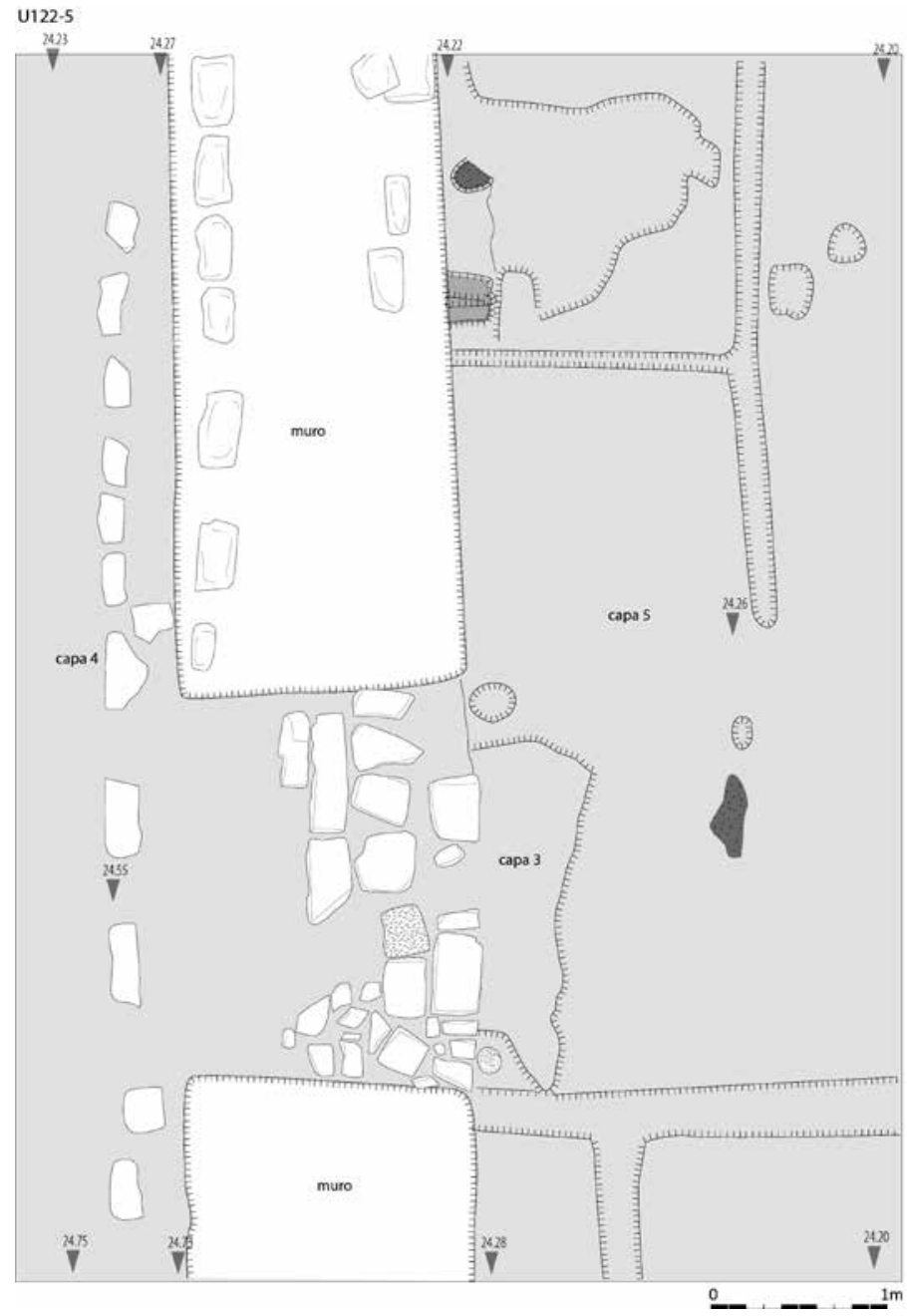

Figura 16. U122-dibujo de planta 
PETER EECKHOUT Y MILTON LUJÁN DÁVILA

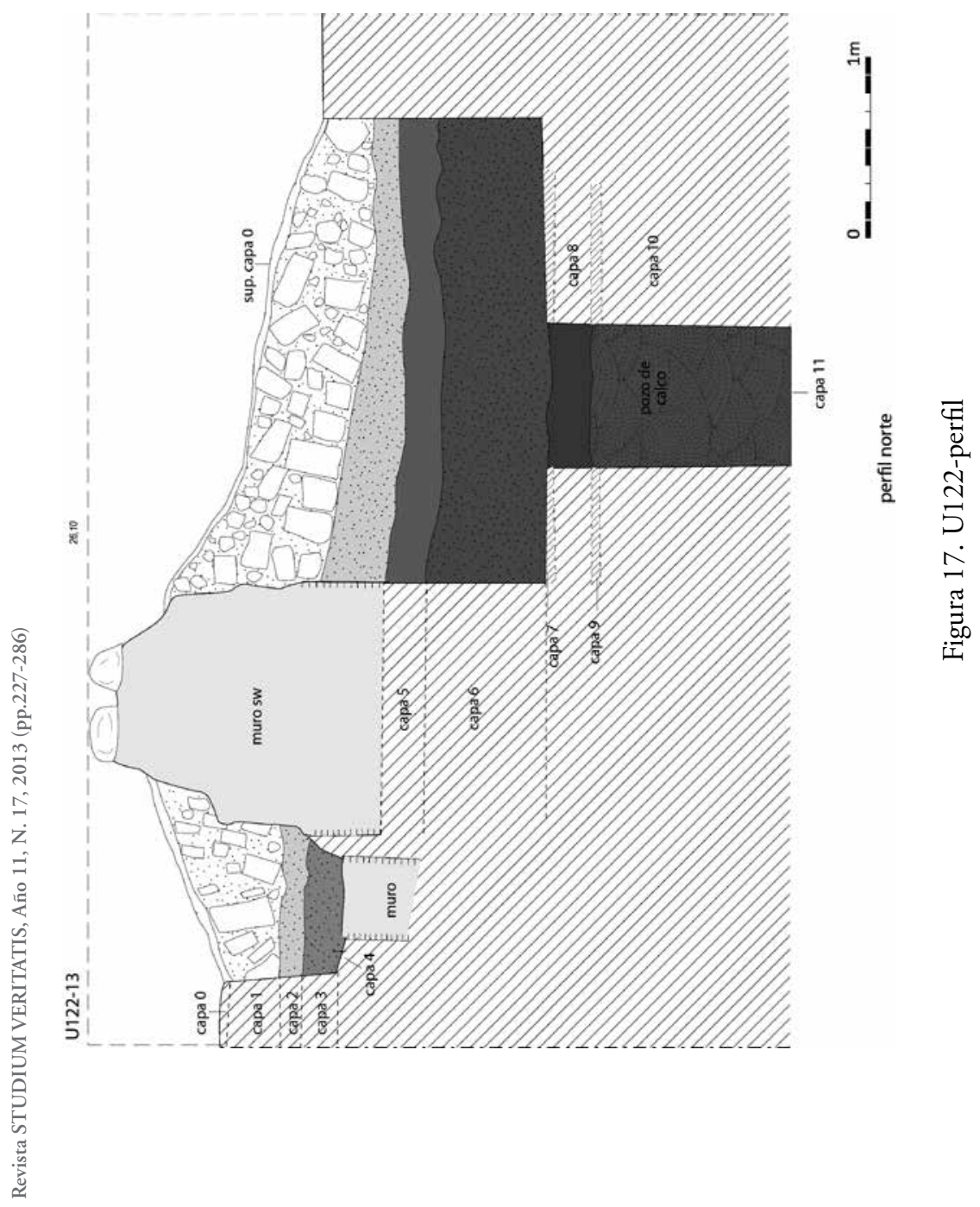




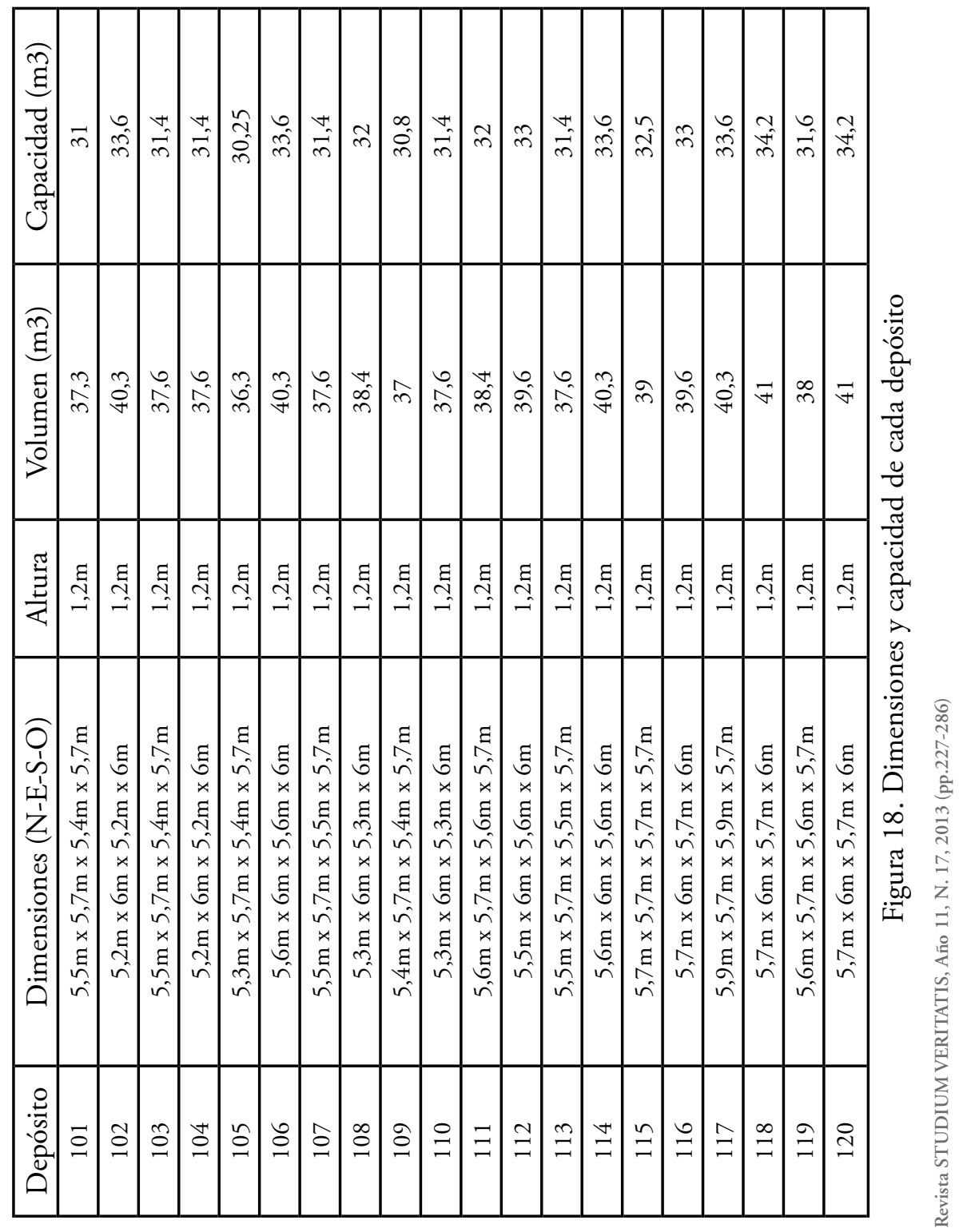




\begin{tabular}{|c|c|}
\hline Taxones & Porcentaje \\
\hline Maíz & $98,04 \%$ \\
\hline Maní & $66,67 \%$ \\
\hline Ají & $54,9 \%$ \\
\hline Madera & $50,98 \%$ \\
\hline Carbón & $47,06 \%$ \\
\hline Zapallo loche & $41,18 \%$ \\
\hline Algodón & $37,25 \%$ \\
\hline Guayaba & $37,25 \%$ \\
\hline Lúcuma & $21,57 \%$ \\
\hline Mate & $17,65 \%$ \\
\hline Zapallo macre y calabaza & $11,76 \%$ \\
\hline Frijol & $11,76 \%$ \\
\hline
\end{tabular}

Tabla 1. Frecuencia de los taxones en las muestras procedentes de las excavaciones en el E8 (Stellian 2012) 